\title{
Cuatro enterramientos calcolíticos en hoyo del Cerro de la Cabeza (Ávila)
}

\author{
Four Copper Age Pit Burials from Cerro de la Cabeza (Ávila)
}

\author{
J. Francisco Fabián García*, Antonio Blanco González** \\ *Servicio Territorial de Cultura. Junta de Castilla y León. Plaza Fuente el Sol 1. 05001-Ávila. jfranciscofabian@gmail.com \\ ** Department of Archaeology. Durham University. South Road. Durham-DH1 3LE (UK). ablancoglez@gmail.com
}

Recibido: 17-01-2012

Aceptado: 20-04-2012

\begin{abstract}
RESUMEN
En este trabajo se describen en detalle las cuatro fosas funerarias de época calcolítica descubiertas en un campo de hoyos objeto de una excavación de urgencia. Se trata de una fosa múltiple con seis individuos con claras pruebas de violencia y tres fosas individuales. En todos los casos se practicó la inhumación de los cadáveres, y se recuperaron indicios claros de enterramientos secundarios en alguna de sus formas posibles. Se presentan de forma individualizada los resultados obtenidos de cada fosa, incluyendo información sobre los restos de cultura material hallados en el relleno junto a la ofrecida por los estudios de antropología física, paleopatología, paleodieta, arqueopalinología y las cinco dataciones de radiocarbono obtenidas de los restos humanos. Por último, se interpretan estos testimonios en el marco cultural de su época, insistiéndose en su consideración de enterramientos extraordinarios o de relegación, al margen de la pauta funeraria normativa.
\end{abstract}

Palabras Clave: Calcolítico. Campo de hoyos. Inhumaciones en hoyo. Violencia prehistórica. Submeseta Norte.

\begin{abstract}
This paper presents a thorough description of four pit burials dated to the Copper Age and recovered during the rescue excavation of a pit site. The lot consists of a multiple pit burial containing six individuals with clear proofs of violence plus three other single pit burials. The inhumation was the funerary treatment followed in all cases and proofs of secondary burial have been also documented. Data on material culture, physical anthropology, paleopathology, palaeodiet, archaeopalinology and radiocarbon dating of the human remains are included for each burial pit. The paper proposes an overall archaeological interpretation of these funerary testimonies in their cultural context. Their probable extraordinary character is highlighted, as relegated burial cases at the margins of the everyday normative mortuary rules.
\end{abstract}

KeY words: Copper Age. Pit site. Pit inhumations. Prehistoric violence. Northern Meseta.

Sumario 1. Introducción. 2. El yacimiento. 3. Enterramiento 1 (colectivo). 4. Enterramiento 2. 5. Enterramiento 3. 6. Enterramiento 4. 7. Análisis y discusión de los enterramientos. 8. Los enterramientos del Cerro de la Cabeza en su contexto geográfico y cultural. 


\section{Introducción}

En 1997 el proyecto para construir la carretera de circunvalación de la autovía A-51 para la ciudad de Ávila contemplaba su afección sobre el yacimiento arqueológico conocido como Cerro de la Cabeza. Éste en principio se vería afectado de una forma mínima y colateral en relación a lo que entonces se suponía que era su núcleo principal, conformado en torno a un promontorio rocoso granítico. La excavación $^{1}$ en área de la zona afectada implicó a una superficie de $5.200 \mathrm{~m}^{2}$ (Fig. 1). En una publicación previa nos hicimos eco de uno de los hallazgos funerarios deparados durante dicha excavación, que propusimos datar en la transición Bronce-Hierro (Fabián et al. 2010). Este trabajo pretende abordar con todos sus detalles particulares los enterramientos calcolíticos documentados, los cuales ya fueron citados de una forma más general en una publicación anterior (Fabián, 2006: 92-99 y 306-318). Conscientes de la importancia y singularidad que revisten tales testimonios para explicar el aspecto funerario del III milenio AC en la Meseta, es nuestro propósito también ahondar a través de su aportación en el debate sobre la muerte, sus manifestaciones y su trascendencia social en aquel contexto histórico.

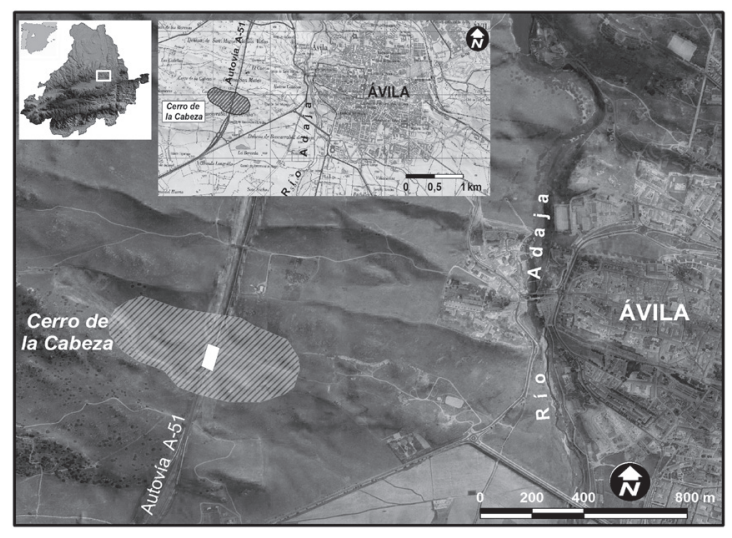

Figura 1.- Localización del yacimiento del Cerro de la Cabeza en el marco de la provincia de Ávila y detalle de su ubicación al oeste de la capital abulense.

\section{El yacimiento}

El yacimiento del Cerro de la Cabeza se emplaza en el Valle Amblés, una pequeña y muy bien definida unidad geográfica que forma parte de la estribación norte del Sistema Central, constituyendo el último escalón con estructura montañosa hacia las campiñas del valle del Duero. Situado su fondo de valle a una altitud media de $1.100 \mathrm{~m}$, surcado longitudinalmente de oeste a este por la cuenca alta del río Adaja, afluente del Duero, tiene una superficie de fosa de $230 \mathrm{~km}^{2}$. Aunque hay indicios de ocupación paleolítica, será primero en el Neolítico y sobre todo en el Calcolítico cuando la explotación de sus tierras alcance una importancia notable, tanto cualitativa como cuantitativamente (Fabián 2006).

El yacimiento se encuentra en la parte oriental del Valle Amblés, sobre su reborde norte, que constituye la subunidad conocida como Sierra de Ávila. Ésta, a la altura del yacimiento, consiste en un horst granítico ya de poca envergadura respecto a su extremo oeste, pero suficientemente significativo frente la llanura aluvial del fondo del Valle Amblés, con un desnivel en ese punto de entre 80 y $60 \mathrm{~m}$. Se trata de una zona amesetada presidida por un promontorio granítico constituido por grandes bolas agrupadas en determinados puntos, dispersándose en sus inmediaciones en formaciones de menor envergadura. Este emplazamiento constituye un lugar suficientemente destacado sobre las tierras del fondo del valle y abrigado del norte en buena parte por la suave inclinación de la meseta donde se encuentra. El río Adaja circula a $2 \mathrm{~km}$ al este y queda por el sur flanqueado por el arroyo estacional de Duruelo, inmediato a su confluencia con el Adaja, configurándose una pradera húmeda de buenos pastos. Por otro lado en la actualidad se constatan varios manantiales dentro del propio yacimiento y en su inmediatez. A estas circunstancias hay que unir otra muy importante, tal vez primordial para entender algunas de las circunstancias que rodean este yacimiento: la presencia de carbonato de cobre o malaquita asociada al granito, la cual se presenta fundamentalmente -que conozcamos- en forma de finas plaquitas adheridas a la ganga. El lugar presenta, además, notables cualidades de aprovechamiento agrario, con buenos pastos -tanto en los campos del reborde granítico como en la vega húmeda inmediata al sur del yacimiento-, y suelos aptos para la agricultura en la cercana planicie sedimentaria.

El yacimiento es un típico campo de hoyos, resultado de ocupaciones posiblemente recurrentes y discontinuas durante milenios. Así, las fosas se rellenaron con materiales que indican una secuencia cultural que abarcaba desde el Neolítico Final hasta el Hierro I. Los dos niveles que en general antecedían la presencia de las fosas mezclaban materiales correspondientes a toda la secuencia cultural, mostrando el gran trasiego del lugar fomentado por la poca profundidad a la roca madre. La extensa secuencia cultural del yacimiento lo convierte en el único conocido en la zona con un desarrollo temporal tan dilatado, algo que podría atribuirse al beneficio de la malaquita. No parece casual que se inicie en los primeros momentos en los que el cobre se explota en la zona y se abandone cuando el hierro 
comienza su circulación y el bronce pierde valor. Posiblemente la zona excavada en 1997 conforma un sector marginal en la que las estructuras eran principalmente de tipo negativo (Fig. 2). La mezcla de fosas correspondientes a los diferentes momentos de ocupación compone un paisaje arqueológico literalmente marcado por la presencia de los conocidos pozos, fosas o cráteres excavados en la roca, los cuales fueron documentados en un total de 385 . Los materiales hallados en el interior de tan controvertidas estructuras (Díaz del Río 2001; García Barrios 2007; Carmona Ballestero 2012), parecen mostrar que fue en el Bronce Final y en la primera Edad del Hierro cuando se excavaron en mayor cantidad. No son pocos los hoyos que aparecen colmatados con materiales calcolíticos y de hecho los enterramientos se situaron en una zona donde era habitual excavar este tipo de estructuras. Se trata además de un sector que en principio, atendiendo a la dispersión de restos en superficie, fue diagnosticado como un área marginal del yacimiento respecto al hipotético foco principal.
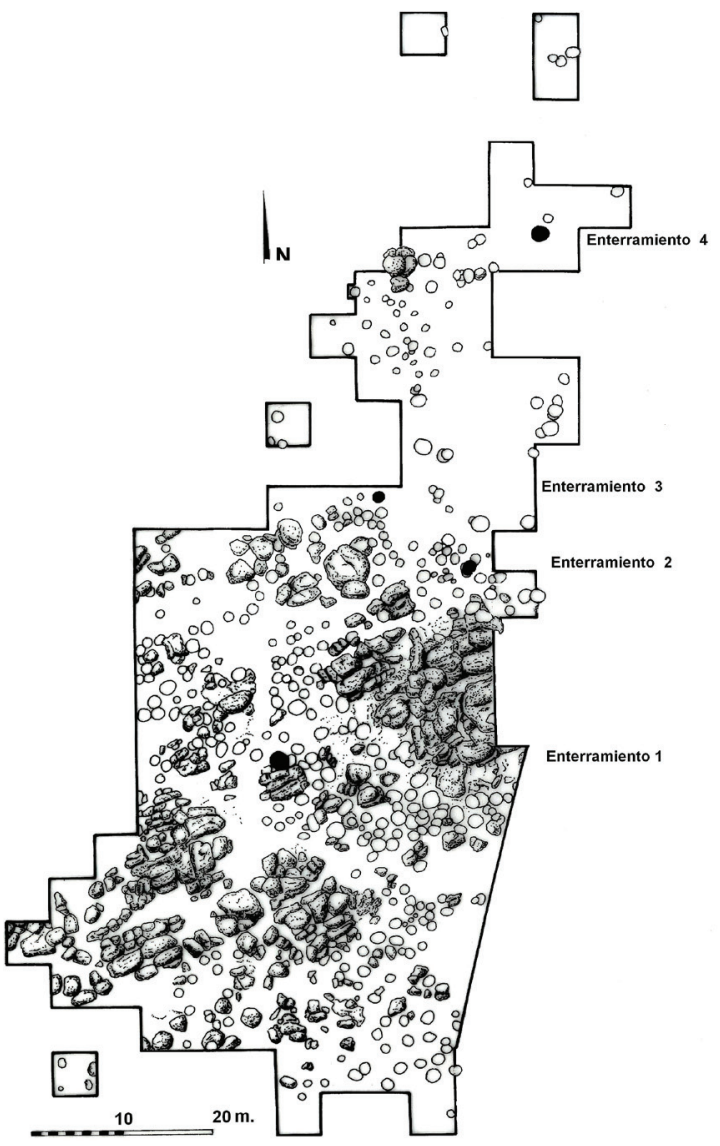

Figura 2.- Planta de la zona excavada en 1997 con la generalidad de las estructuras excavadas y localización de las 4 fosas con enterramientos calcolíticos.
Finalmente hay que señalar que el Cerro de la Cabeza es uno más de los 71 yacimientos de habitación atribuibles al Calcolítico conocidos en el Valle Amblés, la mayor parte de ellos en su reborde norte. No abundaremos en las características culturales de este período porque han sido abordadas en otros trabajos (Fabián 2006; Blanco 2008).

\section{Enterramiento 1 (colectivo)}

El lugar elegido para el enterramiento se encontraba cercano a un promontorio granítico bien destacado, compuesto por grandes cantos redondeados agrupados y de cierta altura. Este promontorio era el más evidente de todos los que de una manera más humilde integraban la zona. El punto concreto elegido carece de cualquier protagonismo evidente que se hubiera buscado para dar realce a la tumba. Unicamente cabe pensar que se eligió quizá con premeditación un lugar junto a una roca destacada en 1,30 $\mathrm{m}$ del nivel de apertura de la fosa (Fig. 3), cuyas características podrían haberla hecho propiciatoria y partícipe de una posible ceremonia, la que hemos reconstruido idealmente en la Figura 8. Esta roca, con una plataforma plana en su cima de aproximadamente $10 \mathrm{~m}^{2}$ de superficie, podría haber servido tal vez para que uno o varios individuos pudieran asistir a la ceremonia funeraria en una posición elevada sobre la fosa funeraria y sobre los demás participantes del evento.

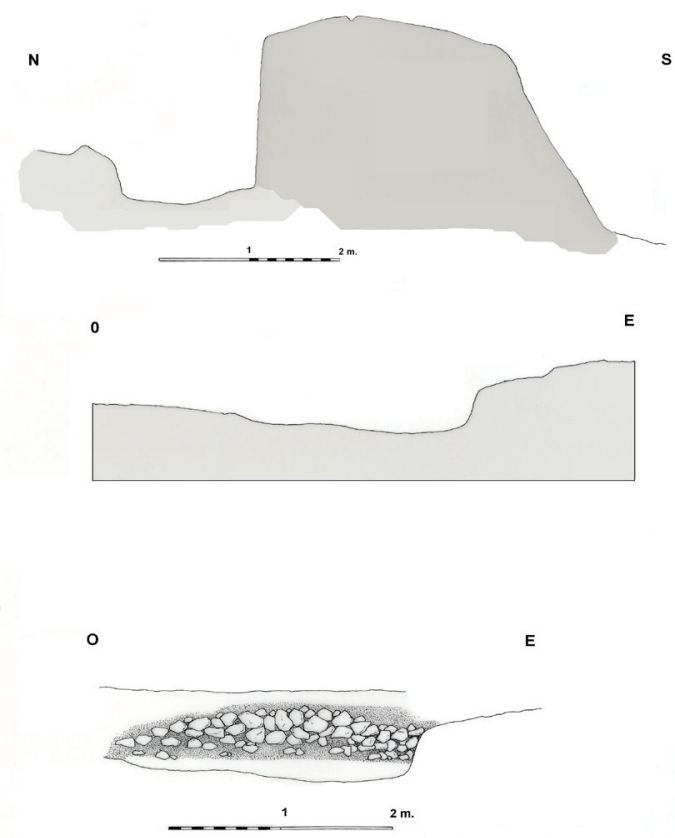

Figura 3.- Enterramiento colectivo. Secciones de la fosa y del túmulo. 
El enterramiento de varios individuos se llevó a cabo en una fosa abierta en el sustrato virgen constituido por granito alterado, de fácil excavación. Las dimensiones de la fosa (2,05 por $1,83 \mathrm{~m})$ y su escasa profundidad $(0,50 \mathrm{~m})$ hacen pensar que fue excavada expresamente para el enterramiento, pues no se parece a la mayoría de los hoyos documentados en el yacimiento, más estrechos y profundos. El fondo es prácticamente plano excepto en una pequeña zona donde se inclina a causa del afloramiento de la roca granítica más dura y compacta y por tanto más difícil de rebajar. Esa zona, en ligera pendiente, se evitó a la hora de depositar los cuerpos. En el fondo de esta fosa fueron introducidos un total de 6 cadáveres (Figs. 4, 5 y 6) una vez pasada la fase del rigor mortis, puesto que se observa cómo los miembros fueron manipulados sin problemas para ser adaptados a las condiciones de la fosa o colocados en una disposición preconcebida. No hubo un patrón general de ordenación de los cadáveres. Salvo los dos primeros en quedar depuestos en la base de la fosa (individuos 5 y 6), ambos con similitudes muy claras en la postura, los demás fueron dispuestos con diferencias sustanciales (Fig. 6). No aparecieron restos muy concretos de algunos de los cadáveres, como por ejemplo los huesos del pie a partir de tobillo del individuo 6, un pie del 1, la parte de la pierna, de la rodilla al pie, del individuo 2 y una mano del 4 . La posibilidad de que hubieran desaparecido con el tiempo no resulta factible, dadas las óptimas condiciones de conservación de toda la muestra.
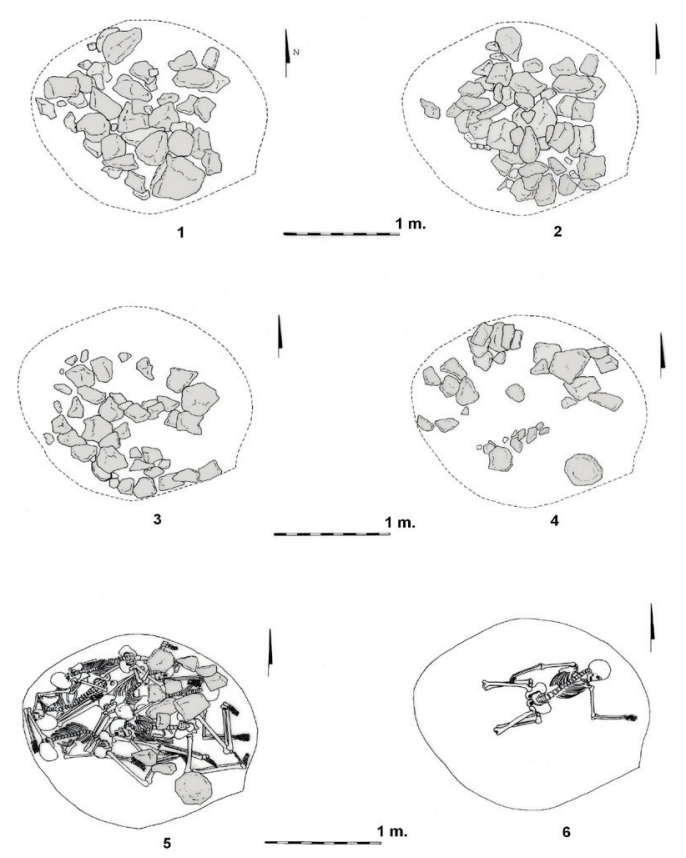

Figura 4.- Enterramiento colectivo. Distintas plantas correlativas del túmulo.
Los dos primeros cuerpos en ser colocados, el 6 y el 5, lo fueron en paralelo y en orientación (este a oeste, con el cráneo al este) inversa a los otros cuatro que se colocarían después. Ambos tenían las piernas flexionadas hacia atrás apoyando los talones en los glúteos (Figs. 5 y 6). En ambos casos el brazo derecho quedaba extendido paralelo al cuerpo, mientras que el izquierdo se levantaba perpendicular al cuerpo, flexionándose en ángulo recto, coincidencia que no parece casual. Una vez finalizada la deposición de todo el conjunto, se colocó un círculo $(60 \mathrm{~cm}$ de diámetro $)$ muy tosco de piedras de tamaño mediano (Fig. 5) sobre los cráneos de estos dos individuos (ambos masculinos, de $30 / 35$ y $25 / 30$ años y 1'64 y 1'62-1'68 m de estatura respectivamente). Dos de las piedras fueron emplazadas parcialmente sobre cada uno de los cráneos. Del sedimento interior se tomó una muestra estudiada por el palinólogo J. Antonio López Sáez cuyo resultado no dio ninguna pista útil para esclarecer la deposición, por ejemplo, de algún elemento vegetal. A continuación fueron dispuestos los cadáveres de los individuos 2 (varón de 35/40 años y 1'55-1'62 m) en decúbito lateral izquierdo y el 3 (mujer de 18/20 años y 1'47 m) en paralelo, en decúbito lateral derecho flexionado, adaptándose el cuerpo de ambos al perfil de la fosa en el arco noroeste (Fig. 6). A continuación, con sólo la mitad norte de la fosa ocupada, se depositó el individuo 1 (varón de 15/16 años y 1'63 m de altura) en la misma orientación que el 2 y el 3, pero en decúbito supino. Llaman la atención algunos detalles de su deposición, como la postura del brazo izquierdo, perpendicular al cuerpo, flexionando el antebrazo hasta tocar la mano con el cráneo. Asimismo las piernas muestran una disposición curiosa en la que el miembro inferior derecho está extendido hasta la rodilla, mientras que la pierna izquierda se flexiona formando un ángulo recto. El brazo derecho de este individuo debió estar colgando mientras le colocaban, porque parte de él quedó debajo del glúteo a la altura del codo. El pie derecho a partir del tobillo no apareció, incidencia también apreciada en el individuo 6. Puesto que durante la excavación no fueron hallados los huesos que faltan, estas ausencias parece responder a circunstancias previas a la deposición. Finalmente fue colocado el individuo 4 (varón, 25/30 años, 1'64-1'69 m). Habiendo sitio suficiente a la derecha del individuo 1 para colocarlo en paralelo e incluso a su izquierda, entre el 1 y el 2 , se quiso ponerlo en decúbito supino más abajo, aún a costa de flexionarle las piernas para que pudiera caber en la fosa, situándole la cabeza a la altura del inicio del muslo. 


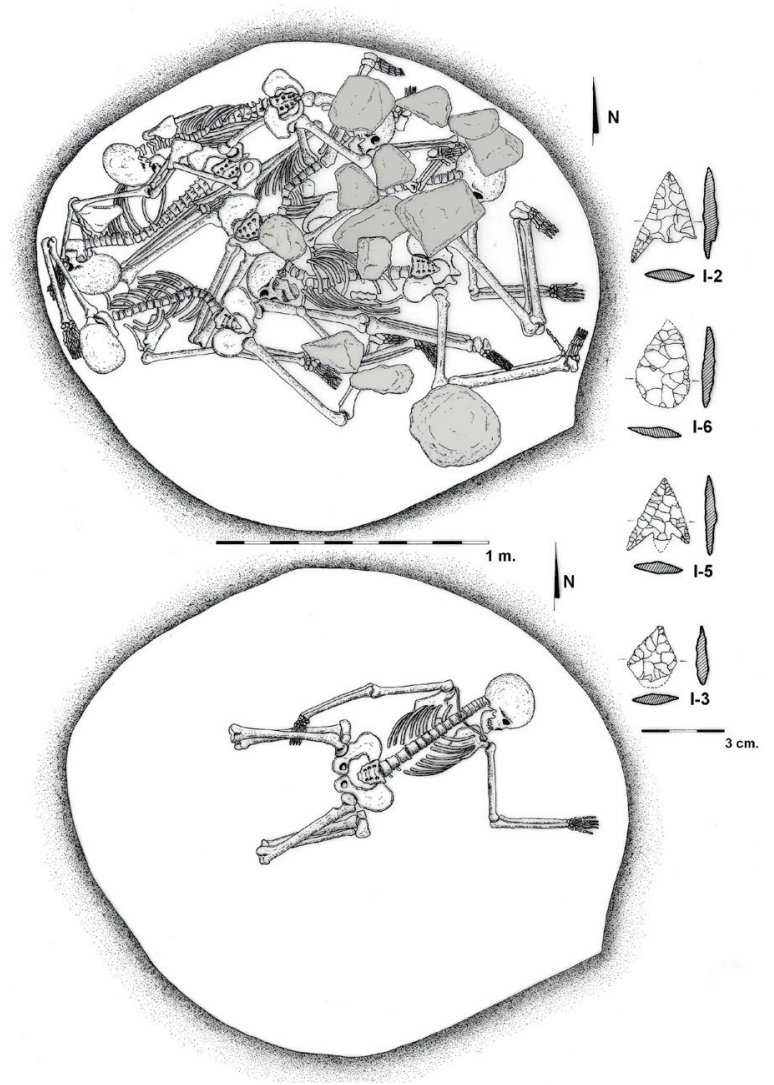

Figura 5.- Enterramiento colectivo. Planta del depósito funerario, detalle del individuo masculino $\mathrm{n}^{\circ} 6$ depositado debajo de los demás y representación de las cuatro puntas de flecha de sílex alojadas en los cuerpos.

Una vez llevado a cabo el enterramiento, la fosa fue colmatada con una capa de tierra que cubrió los cadáveres por completo, sobresaliendo incluso en algunos centímetros respecto a la rasante del inicio de la fosa. A esa altura fueron depositados tres fragmentos de recipientes cerámicos que constituyen la mitad de la pieza original. Todos eran pequeños recipientes de 12,11 y $9 \mathrm{~cm}$ de diámetro en la boca respectivamente, definibles tipológicamente en líneas generales como cuencos semiesféricos (Fig. 7). Uno de ellos estaba decorado con un cordón plástico corto, en semicírculo y posiblemente con otro motivo diferente espaciado del anterior del que ha quedado sólo parte de la huella inconcreta. La decoración de este fragmento no es conocida en los poblados calcolíticos de la zona. Dentro de su escasez, curiosamente tres recipientes con esta decoración fueron hallados tambien en ambientes funerarios, en la tumba 1, de cronología calcolítica, de Los Churuletes (Purchena, Almería), como también en El Garcel (de la Peña 1986: 83 y 123). En el Cerro de la Cabeza sólo este recipiente es de factura cuidada, los otros dos son muy toscos, apenas alisados,

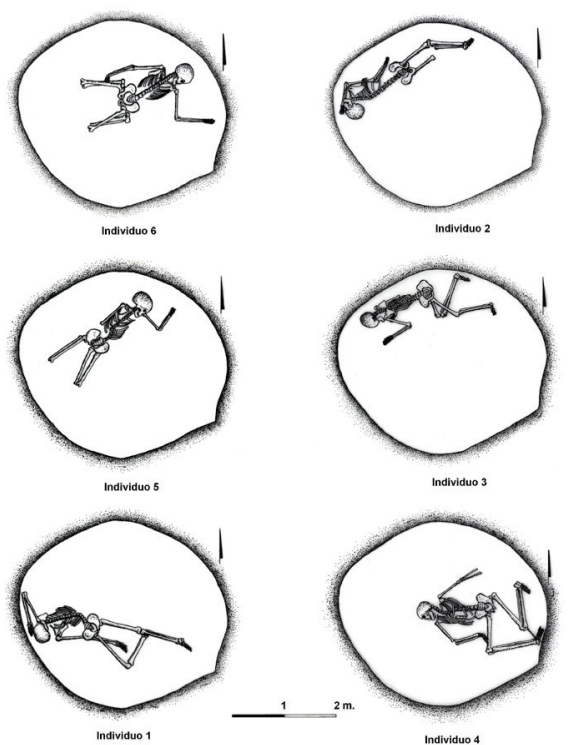

Figura 6.- Enterramiento colectivo. Distintas posturas de los cadáveres en el orden correlativo de deposición de los mismos. 
como si procedieran de la improvisación a partir de un pegote de barro fresco. Posiblemente un cuarto fragmento también deba relacionarse con ellos; es el $25 \%$ de un pequeño cuenco de buena factura. Todos estos fragmentos de recipientes estaban inmediatos, colocados de manera deliberada. El hecho de que no fueran expresamente incluidos junto a los cadáveres plantea dudas sobre su interpretación como ajuar, y tal vez pudieran relacionarse con una comida o bebida rituales celebradas durante el episodio funerario, algo ya intuido en otros casos coetáneos (p.e. Garrido-Pena et al. 2011). Entre la tierra de colmatación de la fosa se reconocieron algunos otros fragmentos cerámicos más, a los que por su reducido tamaño y por pertenecer a recipientes de mayor envergadura original les atribuimos un carácter no premeditado (aunque seguramente percibido por los enterradores prehistóricos) en el enterramiento, como también a algunas esquirlas de hueso y carbones de pequeño tamaño. Las cerámicas descritas representan las formas habituales durante el Calcolítico en la zona (Fig. 7).
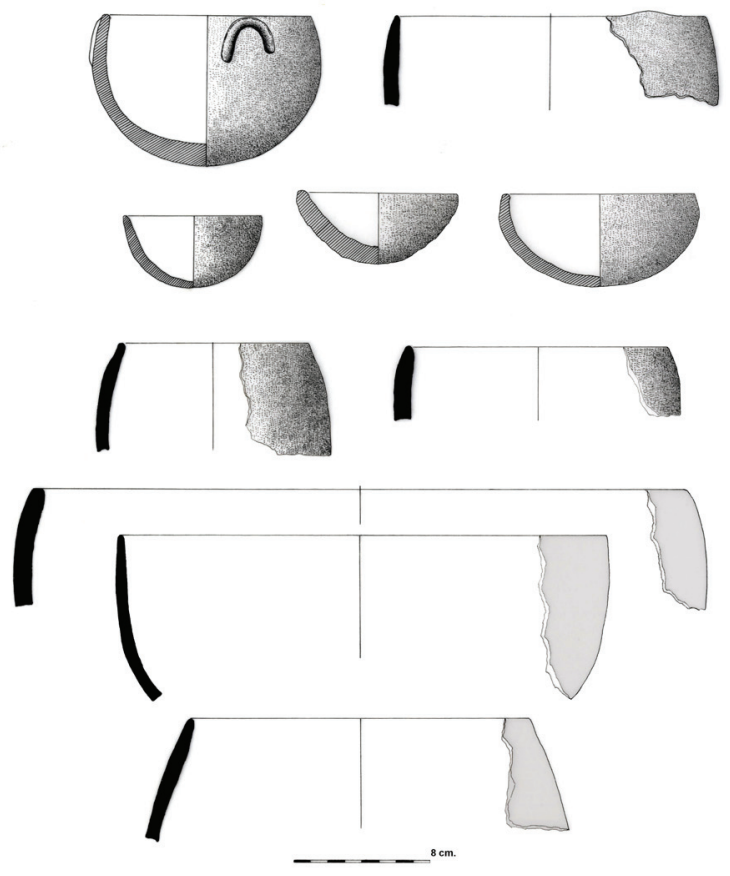

Figura 7.- Cerámicas asociadas al enterramiento colectivo. Los fragmentos dibujados enteramente corresponden a los casos más completos.

Tras la mencionada cubrición con tierra de todo el depósito funerario, fue construido sobre la fosa un pequeño túmulo de piedras de $0^{\prime} 40 \mathrm{~m}$ de alto con elementos de mediano tamaño (Figs. 3-4). Parece significativo que una de las piedras del túmulo primeramente colocadas sobre la tierra que cubría los cadáveres, fuera un fragmento de roca con malaquita. Sea o no casual su posición e incluso también el hecho de que se encuentre formando parte del túmulo, lo que como mínimo indica es que en el lugar había fragmentos de roca con malaquita, quizá producto de la acumulación de mineral para la fundición.

El levantamiento minucioso de los huesos permitió reconocer detalles de gran interés para la interpretación del enterramiento; nos referimos al hallazgo en el interior de cuatro de los cadáveres -individuos 2, 3, 5 y 6- de puntas de flechas de sílex (Fig. 5) que indudablemente plantean la cuestión del reconocimiento de pruebas claras de violencia intergrupal prehistórica (Guilaine y Zammit 2002; Esparza et al. 2008). El proyectil del individuo 2 -de retoque plano cubriente con pequeño pedúnculo y aletas asimétricas, una desarrollada y la otra incipiente- estaba clavada en el tórax, claramente en el interior del pulmón. La de la joven (individuo 3) -con retoque cubriente y forma almendrada- estaba alojada en el cuello, entre éste y la mandíbula inferior. La del 5 -con retoque cubriente bifacial y pedúnculo y aletas disimétricas, similar a la del 2estaba alojada en la espalda, inmediata a la cuarta vértebra. Finalmente la del individuo 6 -con retoque cubriente, cuerpo triangular y base convexaestaba alojada en el extremo distal del húmero derecho a la altura del codo, donde había dejado una incisión en el hueso bien marcada. Este individuo, como el número 5, debió de ser alcanzado por detrás. Las de aletas y pedúnculo perdieron buena parte de éste al quedarse dentro del astil en el momento de ser extraídos tales proyectiles del cuerpo. Algo parecido sucedió con la flecha del individuo 3 que perdió parte de la base y también con la del 6, cuyo choque con el húmero fracturó el ápice del proyectil. Un detalle importante a tener en cuenta es la rareza de las puntas de pedúnculo y aletas de sílex en el Valle Amblés y en general en toda la zona abulense. Sólo conocemos dos casos correspondientes al Calcolítico: uno de Los Itueros, en Santa María del Arroyo a unos $20 \mathrm{~km}$ al oeste del Cerro de la Cabeza (Fabián 2006: 219) y otro en El Tomillar, Bercial de Zapardiel (Fabián 2009: 30) a unos $50 \mathrm{~km}$ al norte del Cerro de la Cabeza, igual que los Itueros en un contexto del final del Calcolítico, con fechas equiparables. Si son raras estas tipologías, más aún lo son las de pedúnculo y aletas asimétricas, de las que no hemos hallado hasta ahora otros ejemplares que los dos descritos. Este tipo de piezas, escasas tanto en la versión de base cóncava como en la de pedúnculo, pero presentes en toda la península Ibérica (Beguiristain 1987; Vallespí et al. 1985: 29; Bueno et al. 2000: 
157; Juan 2009; Larrén, 1999: 63; Esparza et al. 2008: 38) provocan en algunos casos dudas sobre su intencionalidad o si son producto de la reparación de una aleta tras su rotura. En cualquier caso y postulando por su intencionalidad en el Cerro de la Cabeza, sorprende que las dos únicas halladas en Ávila se encuentren precisamente dentro de un mismo contexto funerario.

El estudio antropológico realizado por B. Robledo, J. Jori y G.J. Trancho (2000), en el que basamos todos los detalles antropológicos que aquí exponemos, tiene la ventaja para este caso de contar con una población coetánea. Estos especialistas concluyen que las condiciones de vida de los individuos estudiados fueron duras para todos ellos, y afectaron a su crecimiento a través de infecciones intestinales y deficiencias alimentarias (criba orbitaria en los individuos 3 y 4); a la columna vertebral a través de frecuentes hernias discales (individuos 2 y 4) y padecieron artrosis en diversos puntos del cuerpo (individuos 1, 2, 4 y 5) a pesar de la relativa juventud de la mayoría, librándose de ello la única mujer de la muestra (individuo 3), posiblemente por su corta edad (18-20 años). De la intensa actividad habla también la placticnemia en el individuo 2 con evidencias claras del trasiego continuo por terrenos accidentados, así como las inserciones musculares de este mismo sujeto practicando trabajos que exigían el intenso movimien- to de los brazos y que para los antropólogos podría estar relacionado con trabajos de leñador. La vida de este hombre de 35-40 años fue particularmente dura ya que, trabajando mucho, padeció artrosis y hernias discales, e incluso fue objeto de una grave agresión (de la que se recuperó) con fracturas de Parry o de Montegia en ambos cúbitos, además de una fisura en el húmero y traumatismos en el frontal y en los dos parietales, tal vez producto de sucesivos episodios violentos. También el 4 presenta evidencias de una actividad intensa, en este caso transportando objetos pesados mediante el arrastre o el apoyo sobre la cabeza o espalda, circunstancia que le provocó, como al 2, hernias discales en vértebras lumbares y dorsales. Por otra parte se aprecian fracturas, además de las ya aludidas para el sujeto 2, en el individuo 5 , en este caso de clavícula, cuya reducción provocó disfuncionalidad en el lado del brazo izquierdo. También fisuras traumáticas en la parrilla costal del individuo 2. A la vista de lo dicho hasta aquí, no cabe duda de que en particular el individuo 2 fue un hombre de vida intensa, moviéndose frecuentemente por terrenos complicados, llevando a cabo actividades que exigían mucho trabajo con los brazos e incluso siendo objeto de confrontaciones de las que salió mal parado, sobreviviendo hasta que la última de ellas le llevó a la muerte con una flecha clavada en el pulmón.

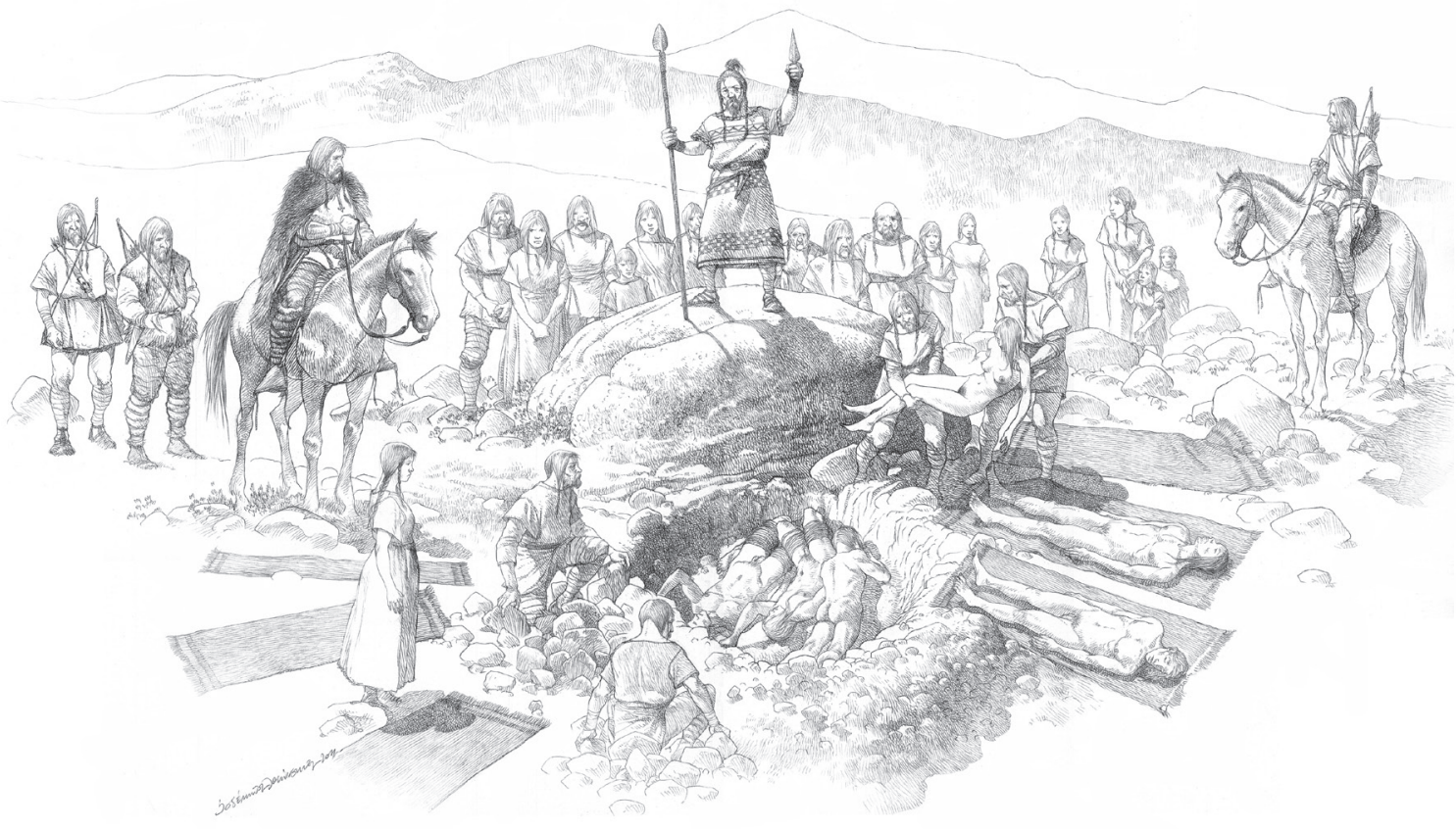

Figura 8.- Reconstrucción del ritual del enterramiento colectivo (Dibujo de José Muñoz Domínguez ${ }^{2}$ ). 
G. Trancho y B. Robledo (1999) también han estudiado la paleodieta de los seis individuos, a base de la detección y combinación de 9 elementos químicos (calcio, fósforo, magnesio, zinc, hierro, vario, cobre, estroncio y vanadio). Concluyen que de forma generalizada esta población se enmarcaba dentro de los parámetros de una sociedad agrícola con un patrón alimenticio basado en el consumo de productos vegetales en el que los cereales, frutos secos, legumbres y bayas marcaban la pauta de su alimentación, con una ingesta media de proteínas de tipo animal. Sólo los individuos 1 (juvenil) y 6 (adulto joven) estaban más cercanos a una alimentación equilibrada, con ingesta combinada de carbohidratos y proteínas. A pesar de la regularidad general de los resultados para todos ellos, hay particularidades dignas de mención como la que presenta la única mujer de la muestra, que tuvo una ingesta vegetal más rica en fibra que los demás, con predominancia de los frutos secos, quizá bellotas, abundantes en el valle Amblés como muestran los estudios polínicos (Fabián 2006). Al ser la única mujer este dato no puede ser asumido todavía como una prueba de diferenciación alimentaria en virtud del género, pero en absoluto debe rechazarse tal posibilidad. De hecho, se trata de una hipótesis de indudable interés que podrá ser matizada en un futuro con nuevos estudios en este sentido.

Dos dataciones de C-14 permiten situar cronológicamente el enterramiento:

- Sobre peroné del individuo 4. Betta-109827: $3970 \pm 50$ BP. Cal. $2 \sigma: 2580-2300$ AC.

- Sobre peroné del individuo 3. Betta-109830: $4020 \pm 50$ BP. Cal. $2 \sigma: 2860-2430$ AC.

Asumiendo que el enterramiento se produjo de forma simultánea y considerando como muy plausible la muerte coetánea de los seis individuos que lo componen, la calibración de las fechas de radiocarbono (Fig. 14) y la combinación conjunta de sus intervalos de calibración permiten situar este episodio mortuorio en el arco temporal de 26202460 cal BC (a $2 \sigma$, con el $95,4 \%$ de probabilidad) ${ }^{3}$.

\section{Enterramiento 2}

Este enterramiento se encontraba a $33 \mathrm{~m}$ al NE del enterramiento colectivo, al otro lado del promontorio granítico ya aludido que dominaba la zona y a $7 \mathrm{~m}$ de la zona de mayor concentración de bloques graníticos. Aparentemente no se trata de un lugar que fuera elegido por alguna singularidad apreciable actualmente (Fig. 9).

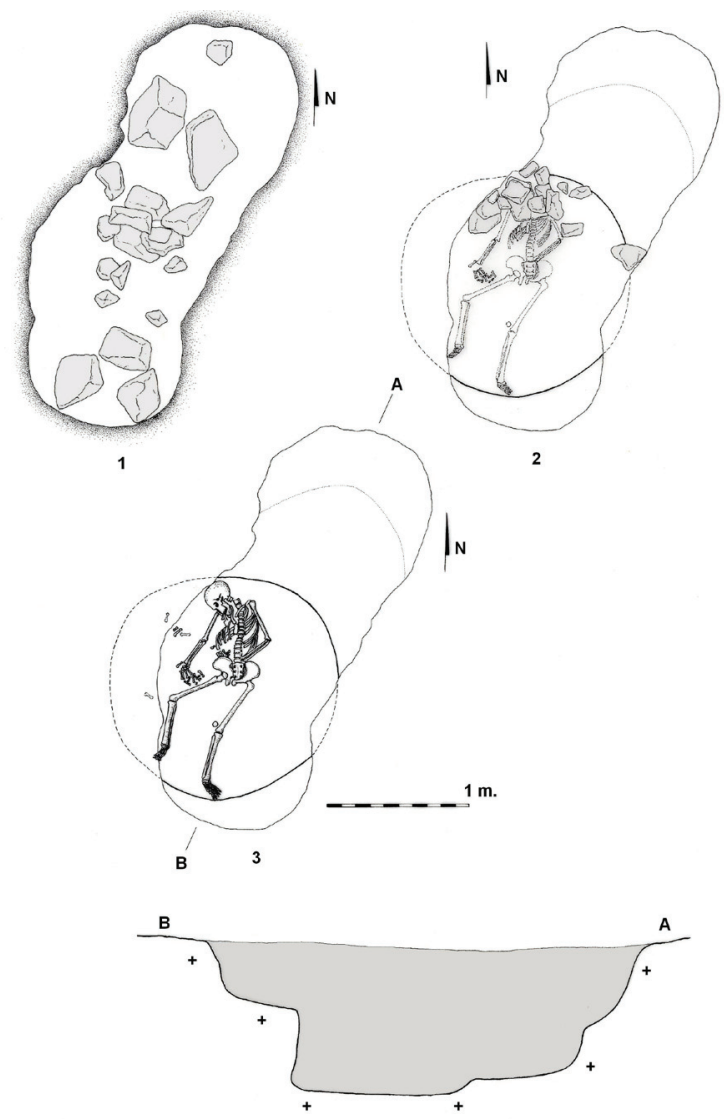

Figura 9.- Enterramiento 2. Plantas sucesivas y sección de la fosa.

La fosa utilizada tenía unas dimensiones en la boca de 1,25 m (E-O) por 1,43 (N-S), siendo algo más amplia en el interior $(1,61 \times 1,55 \mathrm{~m}$ respectivamente). Por tanto las paredes interiores tenían un ligero abombamiento con la boca más pequeña, es decir con perfil siliforme. La profundidad respecto al suelo virgen era de 1,02 m. Fue excavada en granito alterado amarillento y el fondo era plano. Al parecer en su excavación fueron alteradas otras dos estructuras negativas preexistentes e inmediatas, de las cuales una de ellas recortaba a su vez a otra previa. Entre todas, yuxtapuestas, conformaban una alteración de forma aproximadamente rectangular (3,04 $\mathrm{m}$ de S-O a N-E por 1,20/1,01 m E-O), con los extremos redondeados. Posiblemente no estaban amortizadas todas ellas o al menos no totalmente, puesto que a menos de $20 \mathrm{~cm}$ de profundidad se dispuso con la tierra de la colmatación general una capa de piedras longitudinal y discontinua, siguiendo la disposición del cadáver e incluso excediéndole en espacio, posiblemente porque una vez cubierto con tierra ya se había perdido la percepción de los límites que éste ocupaba. 
Hay un detalle que llama la atención a la vista de las acciones extractivas plasmadas en la roca madre: las dos fosas previas a la del enterramiento por el lado N-E llegaron hasta distintas cotas de la roca madre, formando respecto a la fosa funeraria dos escalones regulares, parecidos a dos peldaños que descienden a la tumba. Es posible que no sea más que una casualidad, pero resulta llamativa la regularidad con la que han quedado configurados tales escalones, así como el efecto que surten todas las fosas excavadas en la roca madre y la posición del cadáver, sobre todo considerando soluciones de acceso no muy distintas en algunos enterramientos de tipo hipogeo hallados en Madrid (Blasco et al. 2011).

Las dimensiones de la fosa del enterramiento al parecer resultaron pequeñas para las medidas del cadáver $(1,63 \mathrm{~m})$, colocado en decúbito supino, por lo que al cuerpo tuvo que forzársele ligeramente la cabeza para que encajara (Fig. 9). Pudo haberse buscado otra postura, pero no se hizo. El cuerpo fue colocado en una aparente posición de descanso con la mano izquierda debajo de la pelvis, mientras que el brazo derecho quedaba aproximadamente paralelo al tronco. Su orientación era norte-sur, con la cabeza en el norte. Una vez colocado el cadáver, la cabeza fue cubierta expresamente por una acumulación de piedras de tamaño mediano y pequeño, mientras que la zona superior del tronco y brazo izquierdo se recubrieron con bloques exclusivamente medianos. Asimismo algunas otras piedras de un mayor tamaño fueron dispuestas tras la cabeza y a los pies, agrupadas pero sin cubrir completamente esas zonas y sin entrar en contacto con el cadáver. Parece que la intención de todo ello era ocupar directamente el cadáver. Si las piedras más grandes, las dispuestas a los pies y a la cabecera, no lo consiguieron pudo ser porque el cadáver estaba ya cubierto por alguna capa de tierra y no se calculó con exactitud dónde se ponían. A continuación la fosa fue colmatada con tierra amarillenta muy suelta en la que había abundantes pequeños carbones. Esta tierra no procedía de la excavación de la roca madre, únicamente algunos pequeños bloques habían sido extraídos del granito degradado que constituye aquella. Esto podría indicar que la fosa no fue expresamente excavada para el enterramiento.

Entre la tierra de colmatación de la fosa se documentaron fragmentos de cerámica muy pequeños y dispersos, posiblemente no arrojados de manera deliberada; también pequeños trozos de barro quemado informes procedentes del revoco de estructuras, un fragmento muy pequeño de colador de barro, el pedúnculo de una flecha de sílex con retoque bifacial cubriente, 20 fragmentos de lascas de sílex, 21 fragmentos de cuarzo y 4 de cuarcita, un fragmento de hoja de sección trapezoidal con retoque simple en un filo, un fragmento de morillo, un trozo de roca con abundante óxido de hierro de color rojo en el que se apreciaban huellas de raspado y 46 fragmentos de huesos de fauna en forma de esquirlas de varios tamaños. Sólo el hallazgo de un diente de hoz de sílex a la altura del cadáver, separado del cuerpo $50 \mathrm{~cm}$, suscita la duda sobre si pudiera tratarse de un elemento de ajuar o se hallaba involuntariamente entre la tierra, como suponemos que se encontraba lo demás.

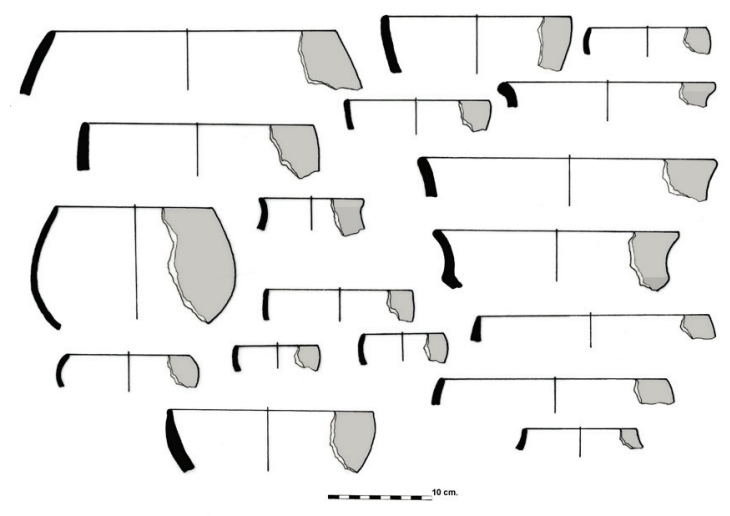

Figura 10.- Enterramiento 2. Formas cerámicas asociadas.

Es necesario mencionar algunos detalles de gran trascendencia que pueden ayudar a interpretar el enterramiento. El primero tiene que ver con la presencia de algunos huesos de dedos y dientes sueltos, es decir, que no se hallaban en su posición original ni en conexión anatómica, y que pudieron pertenecer al sujeto inhumado. De hecho, en el estudio antropológico quedan identificados como correspondientes al propio individuo enterrado, si bien albergamos ciertas dudas ya que se documentaron a 20 y $40 \mathrm{~cm}$ de ambas manos. Algo parecido sucede con algunos dientes exentos, desgajados de su mandíbula de origen. Una posibilidad es pensar que la deposición se llevó a cabo con el cuerpo momificado o en proceso de momificación, por lo que algunos huesos muy concretos pudieron desprenderse durante la manipulación del cadáver para su introducción en la fosa. Sin embargo otra hipótesis es plausible, pues tenemos la presencia de la falange proximal del dedo II de la mano derecha de un individuo adulto, con fuertes inserciones musculares, que nada tenía que ver con el cadáver completo del enterramiento (Robledo et al. 2000), es decir que con seguridad este resto humano corresponde a otro individuo. El hecho de que estuviera en el fondo de la fosa induce a pensar que o bien fue arrojado expresamente cuando se produjo la deposición del cadáver o perteneció a un enterra- 
miento anterior del que no habría quedado más que esa falange, detalle que en principio parece extraño por su exclusividad -no se hallaron otros huesos, si descontamos los dedos y dientes exentos-. Una última posibilidad es que tal despojo humano inconexo hubiera ido mezclado entre la tierra con el resto de los materiales arqueológicos que esta contenía. No es infrecuente encontrar restos humanos sueltos entre los desechos de un lugar de habitación, como hemos comprobado en yacimientos próximos y contemporáneos, por ejemplo en Fuente Lirio (Fabián 2003), Orosordo (Fabián 1999) o Los Itueros (Fabián 2006: 206), todos ellos dentro de la provincia de Ávila.

La datación radiocarbónica sobre una muestra correspondiente a uno de los peronés arrojó la siguiente cronología:

- Betta-109828: $4010 \pm 50$ BP. Calibración a $2 \sigma$ (91.1\%): 2667-2400 AC.

Los datos antropológicos que ofrecemos a continuación se basan, como todos los aquí manejados, en el informe inédito ya citado de Robledo, Jori y Trancho (2000). Se trataba de un individuo masculino de 40-45 años y 1,66-1,66 m de altura, en el que se observan algunas particularidades similares a las ya señaladas para los individuos del enterramiento colectivo. Así, este varón muestra evidencias de una intensa actividad locomotora por terrenos accidentados; hipoplasia provocada por disrupciones en el crecimiento como consecuencia de deficiencias alimentarias y enfermedades en la infancia; hernias discales y aplastamientos de vértebras dorsales y lumbares como consecuencia de la carga de objetos pesados soportados por la cabeza o sobre la espalda y artrosis en columna, cadera, rodillas, codo, muñeca y mano relacionadas con una actividad física dura con patrón de carga severa. También aquejó una fractura en el peroné, acompañada de infección postraumática, así como una fractura de falange proximal del dedo $\mathrm{V}$ del pie izquierdo y una lesión tumoral en el trapecio de la mano derecha. Finalmente se le observaron caries y abscesos indicadores de infección intradental así como la pérdida ante mortem de tres molares.

Respecto a los materiales recogidos hay que decir que todos ellos componen una muestra uniforme y acorde con el ambiente calcolítico conocido en los hábitats del valle. Las formas cerámicas son las habituales de los asentamientos calcolíticos de la zona. Entre ellos hay una cazuela de carena media-baja, tipo habitual al final del calcolítico (Fabián 2006: 217) en ambientes donde la presencia del campaniforme es bien patente. En este momento y en los inicios del Bronce Antiguo este tipo de cazuelas proliferarán más. Una muestra aparece en la fosa funeraria campaniforme de Valdeprados, a poca dis- tancia del Cerro de la Cabeza (Gómez y Sanz 1994; Fabián 2006: 356).

\section{Enterramiento 3}

Se encontraba a $13 \mathrm{~m}$ al NO del anterior, dentro de una fosa excavada en la roca madre (granito amarillento degradado), casi completamente circular (1$1,02 \mathrm{~m}$ de diámetro), de paredes irregulares, con 0,44 $\mathrm{m}$ de profundidad $\mathrm{y}$ fondo plano. El punto elegido para abrirla no presenta en apariencia ninguna particular apreciable. En esa misma zona se documentaron más fosas supuestamente contemporáneas, la mayor parte de ellas no interseccionadas por otras anteriores o posteriores.
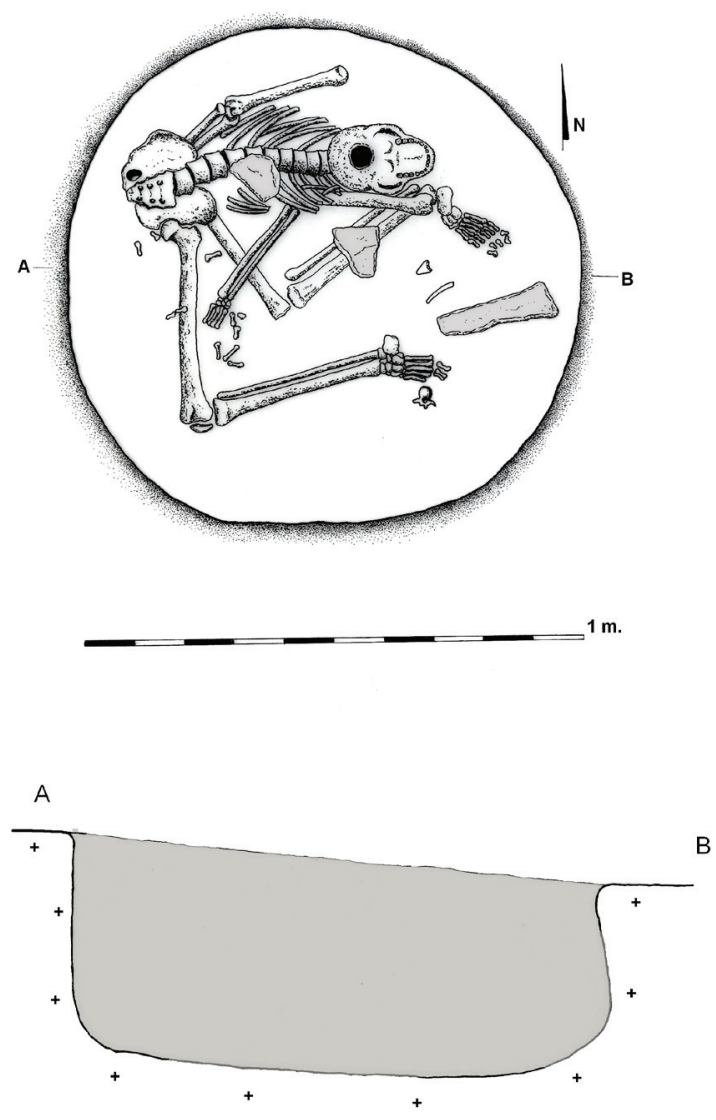

Figura 11.- Enterramiento 3. Planta y sección de la fosa mortuoria.

En el interior de este hoyo, sobre su fondo y sepultado con tierra muy compacta de color amarillento, en la que se observaban algunas motas de carbón, apareció un enterramiento correspondiente a un individuo masculino de 15-16 años y de 1,63 m de estatura (Robledo et al. 2000), en una posición extremadamente forzada (Fig. 11), de manera que el tronco se hallaba 
en decúbito supino, orientado de este a oeste, con los brazos más o menos paralelos al cuerpo. La principal particularidad en la postura retorcida de este joven se halla en la región de la pelvis y las piernas -ambas en la misma dirección y paralelas-, cuyo giro forzado hacia uno de los lados no pudo llevarse a cabo sin una brusca torsión del cadáver a la altura de la cadera. Una hipótesis posible es que el cadáver se encontrara momificado, lo que habría facilitado tal flexión, pues de lo contrario semejante resultado hubiera sido realmente difícil de conseguir. Quizá esta sea la razón por la cual se hayan encontrado algunos huesos de la mano y del pie fuera de su posición anatómica, también algún diente desprendido de las mandíbulas e incluso alguna vértebra cervical muy alejada de la columna vertebral. Precisamente faltan el esternón y algunas vértebras consecutivas de la zona cervical, lo cual unido a la forma de colocación del cráneo, hacen pensar que éste fue depositado después del cuerpo, circunstancia que pudo motivar el extravío de las cervicales que faltan. Parece por tanto muy probable que nos encontremos ante un proceso fúnebre en varias fases (Poyil 2009). El cadáver yacería sin sepultar -con los tejidos secos sobre la piel y conservando las conexiones anatómicas-, en algún lugar preliminar desde el que sería trasladado hasta su destino definitivo. Por algún motivo desconocido el cadáver no se acomodaba a las dimensiones de la fosa mortuoria y fue necesario descoyuntar las cabezas de los fémures respecto a la cadera. Cabe decir que la manipulación y reducción del cadáver pudo haberse llevado a cabo de una forma más delicada, pero no se hizo.

Junto al cadáver tan sólo se localizó un fragmento de hueso largo de fauna, una lasca de cuarcita y trece fragmentos cerámicos de pequeño tamaño, dos de ellos bordes correspondientes a pequeños cuencos semiesféricos simples, que posiblemente estaban entre la tierra de colmatación. El estudio antropológico no revela información adicional a las observaciones ya mencionadas en los restos esqueléticos de las otras fosas funerarias: de nuevo se reconoce la plactinemia, relacionable con una marcada actividad locomotora por terrenos accidentados, la hipoplasia dental, producto de las disrupciones en el crecimiento, artrosis en articulaciones y platibraquia, que sugiere la fuerte actividad del deltoides, músculo encargado de elevar lateralmente los brazos, un aspecto este también señalado en dos de los individuos más jóvenes del enterramiento múltiple.

La datación radiocarbónica sobre un peroné ofrece la siguiente cronología:

- Betta-109829: $3820 \pm 60$ BP. Calibración a $2 \sigma$ (92.4\%): 2463-2134 AC.

\section{Enterramiento 4}

La fosa que lo contenía se encontraba a $65 \mathrm{~m}$ al NO del enterramiento 1 , a $37 \mathrm{~m}$ al $\mathrm{N}$ del enterramiento 2 y a $34 \mathrm{~m}$ al NO del enterramiento 3, en una localización sin ninguna particularidad reseñable que haga pensar en una elección premeditada y característica. La fosa fue excavada en la roca madre de granito degradado amarillento. La boca conformaba una circunferencia casi perfecta de 1,70 m ensanchándose en el fondo, sólo en sentido EO, hasta 2,16 m, formando dos pequeñas oquedades desde la mitad de las paredes hasta el fondo (Fig. 12). El relleno se llevó a cabo con tierras de color amarillento en las que había abundantes fragmentos de cerámica a mano de pequeño tamaño, 22 de los cuales eran bordes y permitieron averiguar la forma original.

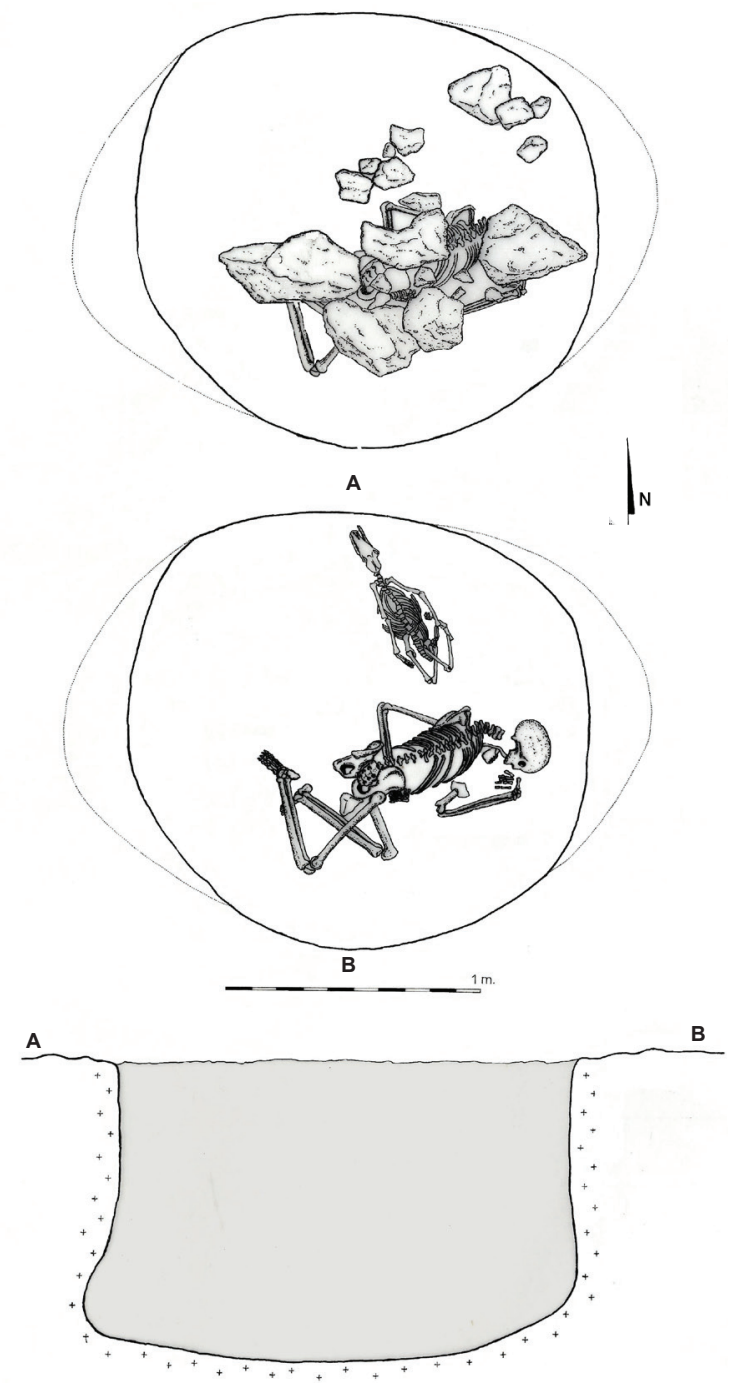

Figura 12.- Enterramiento 4. Plantas y sección. 
El cadáver, orientado de este a oeste, con leve inclinación NE-SO, yacía directamente sobre el fondo de la fosa, a 1,15 m desde su inicio, en posición de decúbito supino izquierdo con las piernas flexionadas, al igual que los brazos, aunque estos en disposiciones diferentes uno respecto del otro: mientras que el derecho se flexionaba llevando la mano hacia la cabeza, quedando una parte bajo ella, el izquierdo, flexionado también por el codo, llevaba la mano a la zona abdominal, quedando ésta en parte bajo la pelvis. El cráneo apareció completamente aplastado. La postura corporal general era de descanso. Como particularidades a señalar hay que decir que le faltaba la mitad proximal del húmero derecho, también un fragmento de la mandíbula inferior, detalles estos que como en los dos enterramientos anteriores, hacen pensar que el cadáver pudo estar expuesto en algún lugar antes de su definitiva inhumación.

Se trataba de un individuo masculino de 1,62 m de altura y de 45-50 años de edad. El estudio antropológico de Robledo, Jori y Trancho (2000) mostró evidencias de criba orbitaria, provocada al parecer por problemas en el sistema inmunitario y la consiguiente susceptibilidad a infecciones posiblemente intestinales. Padeció artrosis en diversas articulaciones, así como aplastamientos en las vértebras dorsales, lumbares y cervicales provocando espondilosis lateral de la L5 como consecuencia de la carga de objetos pesados. Había perdido siete molares a causa de caries pulpares, tenía además tres caries abiertas, fisuras en la parrilla costal y lesiones traumáticas en ambos pies. En este individuo, como en otros del Cerro de la Cabeza con mayor edad, el número de patologías que han dejado huellas en los huesos resulta considerable, precisamente como consecuencia de la vida dura y de la edad. Junto a la cabeza se dispuso un fragmento craneal de otro individuo, también adulto y masculino, cuya particularidad más destacable es una herida inciso-contusa (91x18x2 mm) en el arco superciliar derecho además de, hacia el borde orbitario, otra menor aunque también significativa. Ambas habían cicatrizado.

A espaldas del cadáver se depositó el cuerpo completo de un cánido, separado de él unos $60 \mathrm{~cm}$ (Fig. 12). Se trata de un perro de tamaño medianopequeño. Este testimonio se une a una amplia nómina de casos que señalan a las claras la especial consideración recibida por estos animales domésticos entre las gentes calcolíticas del interior peninsular (Díaz del Río 2001; García Barrios 2007; Esparza et al. 2008; Carmona Ballestero 2012). Por otra parte, a unos $20 \mathrm{~cm}$ del cráneo, bajo una de las dos oquedades contrapuestas en que se ensanchaba la fosa en la zona en contacto con el suelo, había un fragmento grande de la mandíbula de un bóvido claramente depositada en ese lugar. Al lado derecho del muerto y junto a una pequeña acumulación de piedras de tamaño mediano/pequeño, se colocó la extremidad delantera de un ovicaprino, excluyendo la pezuña, con el omóplato, húmero, cúbito y radio en conexión anatómica.

Una vez dispuestos los cadáveres del varón y el perro sobre el fondo de la fosa, así como esas posibles "ofrendas" que les acompañaban, el cuerpo humano fue cubierto con piedras, algunas de un tamaño considerable. Una de ellas, de $0,40 \times 0,30 \mathrm{~m}$, se dispuso directamente sobre la cabeza, aplastando el cráneo y otra, de $0,50 \times 0,30 \mathrm{~m}$, sobre parte de las extremidades inferiores. Las otras piedras que cubrían expresamente el cadáver eran algo más pequeñas. A partir de ese momento la fosa fue rellenada con tierra hasta su colmatación. No se apreció ningún indicio de túmulo.

La datación radiocarbónica obtenida a partir de un peroné del cadáver humano ofrece la siguiente cronología:

- Betta-109831: $3850 \pm 60$ BP. Calibración a $2 \sigma$ (95,4\%): 2468-2140 AC.

En el relleno de la estructura aparecieron, en la forma habitual en los casos de colmatación de fosas, abundantes fragmentos de fauna y cerámica, todos ellos lisos. La apariencia general era que se trataba de desechos. Los fragmentos de bordes que dieron forma (Fig. 13) presentan un elenco típico del Calcolítico local en sus últimos estadios, con alguna presencia de carenas, las cuales suelen aparecer frecuentemente asociadas al campaniforme.

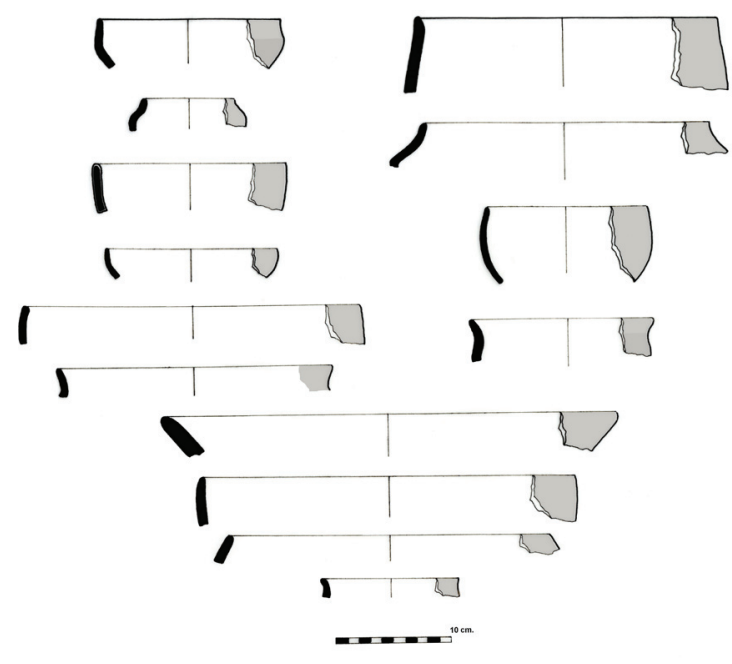

Figura 13.- Enterramiento 4. Cerámicas asociadas. 


\section{Análisis y discusión de los enterramientos}

En líneas generales puede decirse que tenemos cuatro enterramientos en una misma zona de un yacimiento, todos ellos separados entre sí y dentro de un área de $2.101 \mathrm{~m}^{2}$, que fue utilizada, entre otras etapas en el Calcolítico, para la excavación de fosas con boca circular y desarrollo variado, colmatadas finalmente en la mayoría de los casos con desechos diversos, como suele ser habitual. En este yacimiento las tumbas no se agrupan, frente al patrón coetáneo documentado con las inhumaciones acompañadas con campaniforme, que tienden a formar claros espacios funerarios (Liesau et al. 2008; Aliaga 2008: 34; Blasco et al. 1991). No podemos saber si los enterramientos se produjeron simultáneamente en un momento en el que se utilizaba la zona para otros cometidos, integrándose tales pozos como unos contendores más, o si se buscó algún tipo de intimidad funeraria o de vinculación emotiva porque la zona hubiera sido utilizada ya. Lo visto en el enterramiento 2 nos dice que cuando éste se produjo, al menos tres fosas le habían antecedido allí mismo, cortándose entre sí e interfiriendo unas en las otras. Por esta razón los enterramientos que aquí abordamos serán considerados sobre todo desde dos puntos de vista, primero el de su mera existencia en un contexto concreto y luego el de su aportación para el esclarecimiento de la transcendencia en el estudio del aspecto funerario.
El conjunto de los enterramientos se llevó a cabo en fechas radiocarbónicas calibradas a $2 \sigma$ en el amplio intervalo 2667-2134 cal AC (Fig. 14). Ese arco cronológico los sitúa en líneas generales en el final del Calcolítico y, según las fechas más bajas, en los inicios del Bronce Antiguo local, situable en los dos últimos siglos en torno al cambio del III al II milenio AC y definido por un abandono de los hábitats calcolíticos tradicionales (Fabián 2006: 515). Sobre la etapa en la que se produjeron las inhumaciones disponemos de abundantes datos publicados para definir los rasgos generales de la vida desarrollada en el valle, por lo que no vamos a insistir en ello (Ibidem; Blanco 2008). Parece ahora más apropiado reflexionar directamente sobre los datos que aportan los casos aquí presentados en la comprensión del aspecto fúnebre en la segunda mitad del III milenio AC.

En el Cerro de la Cabeza los cuatro casos funerarios aquí descritos pueden reunirse en dos tipos morfológicamente diferentes: uno caracterizado por la inhumación colectiva y otro grupo de tumbas individuales, algunas con otros restos humanos ajenos al enterramiento cuya presencia en la fosa puede atribuirse bien a una ofrenda o bien a un enterramiento anterior, del que habrían quedado muy pocos restos. En el grupo de los individuales, además de compartir el contenedor, les relacionaría entre sí la individualidad de la inhumación y el tratarse en

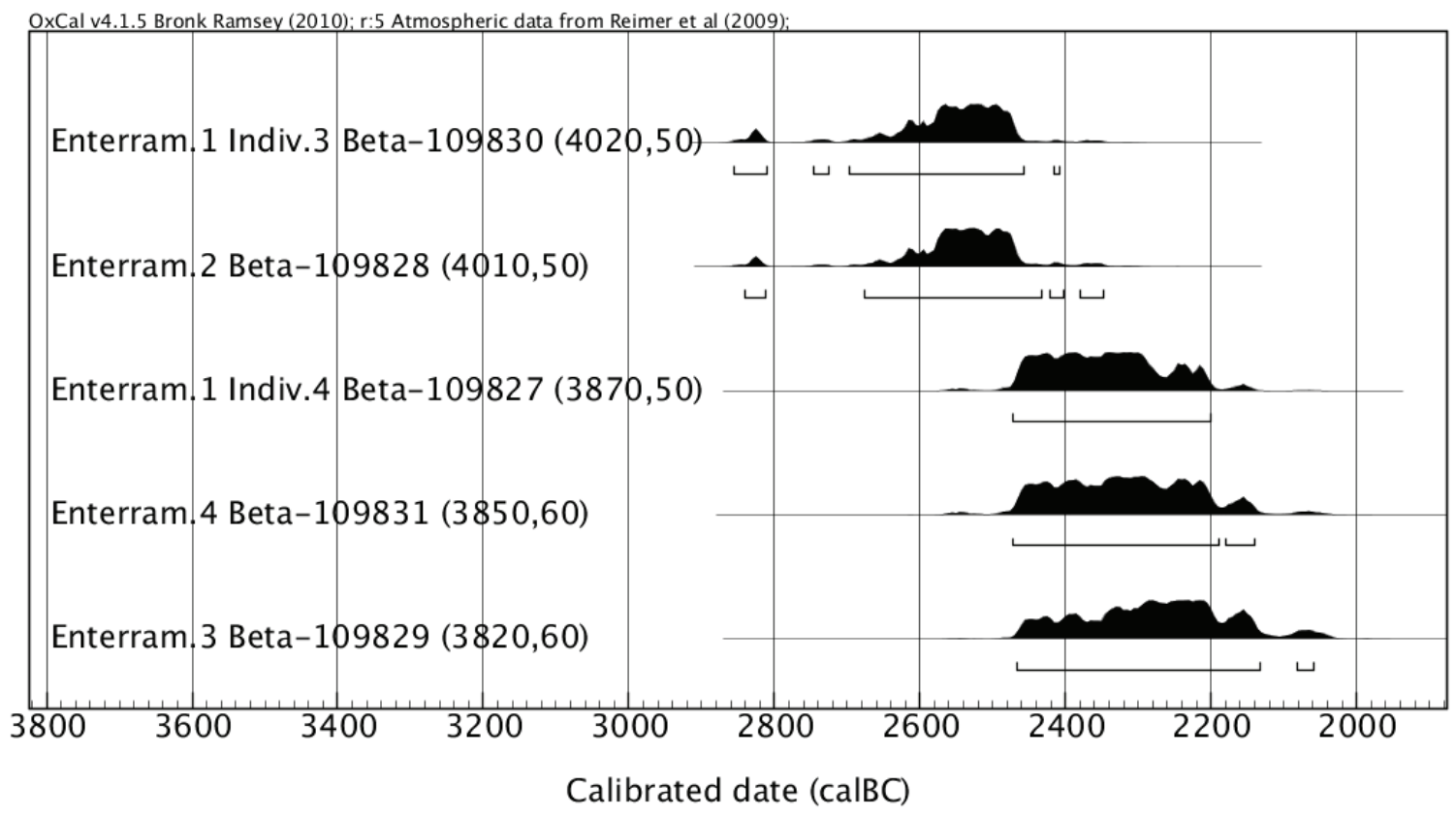

Figura 14.- Representación conjunta de la calibración de las cinco dataciones de radiocarbono obtenidas en los cuatro enterramientos calcolíticos del Cerro de la Cabeza (programa OxCal v.1.4.5). 
todos los casos de varones. No hay una postura física de enterramiento similar en los tres ejemplos, ni comparten orientación los cadáveres. Dos aparecen en posturas corporales que podríamos calificar de descanso, aunque diferentes entre sí. Sorprende la postura tan forzada del enterramiento 3, en la que, como hemos señalado, tal vez pudiéramos ver la necesidad de adaptar un cuerpo momificado o en proceso de momificación a la forma de una fosa ya abierta que no se quiso modificar. Un detalle muy evidente asemeja entre sí a los enterramientos 2 y 4 : en ambos al cadáver es cubierto con piedras parcial (en el 2) o totalmente (4). En el enterramiento 2 es la cabeza expresamente la que se cubre. En el 4 se cubre todo el cuerpo, pero en la cabeza se incide con piedras más grandes, llegando a aplastar el cráneo, aunque no sabemos si ello sucedió pasado un tiempo como consecuencia de la presión o tras colocar el cadáver como una acción ritual expeditiva. Este detalle no es exclusivo del Cerro de la Cabeza pues se conocen más casos, siendo entre ellos el más cercano el de Ciguñuela, en la provincia de Valladolid (Delibes 1987: 48).

Ante semejantes indicios parece claro que se quiso diferenciar el tratamiento de estos muertos frente a otros sin tales formalidades. El hecho en sí merece reflexión pues tal elenco de prácticas -posturas violentadas, mutilación o desmembramiento de cadáveres, cubrición del cadáver con piedras que en algunos casos parecen tener la intención de aplastar alguna parte del cuerpo, etc.- $\sin$ duda guarda un mensaje, quizá como aleccionamiento para los vivos que asisten al sepelio y como práctica necrofóbica, para impedir simbólicamente el regreso de los difuntos o sus espíritus al mundo de los vivos (Esparza et al. e.p.). En suma, todo parece indicar que nos encontraríamos ante posibles casos "de mala muerte" (Velasco et al. 2003), que exigen comportamientos específicos por parte de los oficiantes del sepelio. No parece intrascendente una acción así tras la tragedia que implica una muerte no deseada, ni parece una costumbre generalizada para con todos los cadáveres. Todos estos aspectos inciden en lo ya conocido sobre las pautas que rigieron determinadas deposiciones ritualizadas, dotadas de una indudable carga simbólica, entre las comunidades calcolíticas del interior peninsular (García Barrios 2008).

Un comentario especial merecen los elaborados procesos de tratamiento mortuorio documentados en las tres inhumaciones individuales de varones (enterramientos 2, 3 y 4). Como se ha detallado, en los tres se ha reconocido la presencia de restos inconexos -dedos, dientes- que al menos en dos casos con seguridad no pertenecieron al mismo individuo inhumado: se trata de la falange proximal hallada en el enterramiento 2 y el fragmento craneal de otro individuo -también adulto y masculino-, junto al varón del enterramiento 4 . Ante tales pruebas es posible hablar de la exhumación/conservación, manipulación y redeposición de restos humanos secundarios. Si a ello unimos la desaparición de algunos huesos -húmero derecho, y parte de la mandíbula inferior del varón del enterramiento 4, pies de los individuos 1 y 6 del enterramiento colectivo- la imagen de conjunto hace pensar en este tipo de prácticas, bien documentadas etnohistóricamente (Schroeder 2001; Larsson 2003; Poyil 2009). Al respecto, cabe añadir que este tipo de prácticas están bien constatadas en contextos de hábitat coetáneos, donde no es infrecuente encontrar restos humanos sueltos entre los desechos de un poblado, como hemos visto por ejemplo en Fuente Lirio, Muñopepe (Fabián 2003), Orosordo, en Maello (Fabián 1999) o Los Itueros, Santa María del Arroyo (Fabián 2006: 206). Así pues la amortización definitiva de ciertos restos humanos en muy diversos contenedores parece haber sido el último estadio de unas pautas ritualizadas complejas y muy arraigadas entre tales grupos calcolíticos, que contribuirían a construir la identidad de tales comunidades respecto a sus antepasados (Chénier 2009).

Es complicado averiguar las causas que llevaron a la segregación del conjunto de enterramientos que aquí abordamos respecto al tratamiento habitual a los muertos en la comunidad de la que procedían y que arqueológicamente resultan invisibles. No encontramos muchos indicios visibles que induzcan directamente a formular hipótesis, sólo pistas escuetas. ¿Se trataba en estos casos excepcionales de individuos ajenos a la comunidad principal, por lo que no merecían el mismo procedimiento funerario que la mayoría? ¿Eran individuos a los que se les reservaba otro ritual fúnebre debido a las peculiares circunstancias de su muerte o de su forma de vida? Baste recordar, sin que ello sirva aquí de otra cosa que de reflexión, las distinciones para con la muerte y el tratamiento que se les ha dado hasta no hace mucho tiempo a los suicidas en la cultura cristiana, enterrándoseles fuera del cementerio oficial, en recintos anexos a él, que en muchos casos no tenían ni siquiera puerta de acceso, por lo que había que remontar el ataúd a través de la tapia. $\mathrm{Ni}$ siquiera tenían señal visible de su tumba, e incluso en la Edad Media a algunos se les colocaban grandes piedras encima (Aries 1983; Gómez de Rueda 1997: 181). Sin los datos hoy conocidos ¿qué hubieran podido decir los arqueólogos de hallar casos similares en las excavaciones de los cementerios de hace 30 años hacia atrás? Los enterramientos serían, como los que aquí estudiamos, variados 
también en la forma última, excepcionales siempre, constatables solo en unos cuantos cementerios, evidentemente en los que se habían producido tales circunstancias, lo cual al no saber la causa, nos despistaría buscando las razones por las que en unos sitios se daba y en otros no. Siendo lo más cautos posibles y utilizando la evidencia más básica, pero sin mucha más información, hubiéramos dicho que se trataba de personas a las que se las diferenciaba en el enterramiento respecto del ritual habitual y que eso se hacía por alguna circunstancia desconocida. La razón real era simplemente el suicidio, cosa que no consentía la religión oficial, o el descreimiento. Desconocidas las connotaciones religiosas que el rito había tenido, la hipótesis de que fueran suicidas, no creyentes declarados e incluso apóstatas hubiera sido una entre otras muchas. Lo cierto es que estos enterramientos calcolíticos, que posteriormente continúan en las mismas circunstancias durante toda la Edad del Bronce en la Meseta, distinguían a los enterrados del resto, sea por una razón muy simple y puntual, por razón o razones de más peso o por causas distintas que en lo único que coinciden es en el hecho de la diferenciación formal respecto a una norma.

De los cuatro casos que aquí abordamos, el del enterramiento colectivo posiblemente sea del que podamos aducir alguna hipótesis interpretativa más cercana a su realidad. Podríamos decir que los hechos violentos, a los que suponemos coetáneos y producto de la misma coyuntura general que la que conocieron los enterramientos individuales, por alguna connotación relacionada con ellos mismos, hubieran merecido en este caso un enterramiento unitario con el que distinguir y/o conmemorar un hecho sucedido no habitual, con todos sus significados correspondientes. Entendemos que la construcción del túmulo, por pequeño que fuera y estuviera situado en un lugar en apariencia poco evidente, representaba la constancia y pervivencia durante un tiempo del hecho acaecido, marcado por su presencia visual, si bien no se buscó un lugar especial, muy evidente, tal vez reservado a otros casos que no eran estos. Es bien conocida la costumbre del recubrimiento de fosas funerarias con encachados de piedra, especialmente en asociación con ajuares campaniformes (Martín Valls y Delibes 1989: 39; Aliaga 2008: 27 y 34), como se ha reconocido también en el entorno local (Gómez y Sanz 1994).

En esta ocasión eran gente sin un rango especial, cuyo mérito para ser conmemorados bastó con la construcción de un túmulo en un área de actividad. Posiblemente debamos asociar a unos hechos especiales una ceremonia también especial a su medida, utilizando vasos cerámicos que se rompen, para in- cluir una parte de ellos en el pequeño monumento, que no directamente asociados a los muertos, a los que no les correspondía acompañarse de ajuar, por circunstancias desconocidas. Consideramos como más probable la hipótesis de que los fallecidos lo fueron simultáneamente y como consecuencia de un conflicto, sin descartar por completo otras posibilidades que pueden encontrarse en sociedades prehistóricas, como por ejemplo una muerte ritual. En este sentido no podemos dejar de preguntarnos -sin respuesta- por la causa de que en los cinco cadáveres que tenían flecha clavada, tuvieran una sola todos ellos. El hecho de que uno de ellos no tenga flecha puede significar que murió de otra forma o que la flecha le fue extraída poco antes de la muerte. También nos preguntamos si el que la tenía clavada en el brazo pudo morir por ella (¿envenenada?) o hubo otras acciones más contundentes. Quizá debamos ver en la diversidad de las edades, así como en la presencia de una mujer entre los muertos, no una guerra como tal, sino un conflicto puntual y poco organizado, que se saldó nada menos que con seis muertos, al menos tres de ellos plenamente jóvenes (15/16, 25/30 y 18/20 años), cuyo valor social debía ser elevado, dado que se encontraban en edad de procrear y trabajar con las mejores garantías, contando en el caso de la mujer, además, con que estaba en edad de aportar nuevos y necesarios miembros al grupo. Por otra parte sería un dato muy útil, por lo que de ello pudiera inferirse, conocer el grado de consanguinidad de todos, investigación que se intentó hace diez años, resultando fallida con lo tecnología de aquel momento por no hallarse ADN en la muestra.

Creemos que por más que en otros lugares muy conocidos, como San Juan Ante Portam Latinam (VV.AA. 2007) o el hipogeo del Longar (Armendáriz e Irigaray 1994), los fallecidos por muerte violenta se sumen al resto de los muertos de una comunidad, el caso del Cerro de la Cabeza, con el conjunto de la deposición en un mismo momento y con su túmulo particular, obedece a una circunstancia propia y puntual que no parece admitir en principio muchas más hipótesis bien fundamentadas. En este sentido la propia casuística y las circunstancias del hecho sucedido o de sus consecuencias pudieron motivar la elección de un tipo de ritual concreto, en este caso colectivo porque se trataba de enterrar a los muertos habidos en un conflicto que afectó al conjunto de la sociedad, llevándolo a cabo en esa forma como manera de considerar y evocar ese conflicto, la causa que lo motivó y sus consecuencias. ¿Fue por tanto la propia coyuntura del hecho la que motivó la morfología del enterramiento y además determinó que a los muertos se les diera un tratamiento distinto al del conjunto de 
los fallecidos en la comunidad de la que procedían? ¿Un hecho así era causa para excluirlos del ritual funerario habitual? Posiblemente sí lo era, lo fue de ese modo porque los muertos habituales no merecían una consideración especial, se agrupaban todos juntos sin más en osarios colectivos, en "casas de muertos" o se les hacía desaparecer de alguna forma. La consideración aquí pudo ser precisamente el fallecimiento como consecuencia de un hecho social, un conflicto que afectó a todos. El hallazgo en dos de los fallecidos de puntas de flecha de pedúnculo y aletas asimétricas, completamente extrañas en la zona, inclina inevitablemente a considerar los hechos como consecuencia hipotética de una confrontación con gentes venidas de otro lugar, siendo los fallecidos, como es lógico por el ritual y las flechas alóctonas clavadas, los habitantes del sitio. La ausencia total de puntas de este tipo en la zona y su presencia más frecuente en yacimientos de la provincia de Zamora (Larrén 1999: 63; fig. $16 \mathrm{n}^{\circ} 1$ y Esparza et al. 2008: 38) arroja una nueva hipótesis sobre la procedencia de sus propietarios. Apoyaría de alguna manera esta misma hipótesis una circunstancia que parece evidente para el Valle Amblés, como es la presunta falta de causas potenciales que llevaran a conflictos internos. Observando la idiosincrasia de los asentamientos en todas sus características, no parecen observarse motivos que llevaran, por ejemplo, a conflictos relacionados con la demanda de tierras para la explotación agraria. Ello no quiere decir en modo alguno que se tratara de una vida idílica exenta de problemas, y menos aún que no hubiera conflictos puntuales.

Sin abandonar el terreno de las hipótesis, quizá debamos mencionar que pudo no ser igual en lo relativo a la existencia de veneros de cobre, que en ese tiempo pudo alcanzar una demanda mayor y por tanto algún tipo de presión sobre los puntos de mayor riqueza mineral. La presencia de esos veneros de malaquita en el Cerro de la Cabeza pudo ser entonces un bien muy preciado que ocasionara algún tipo de conflicto muy puntual, ya fuera de orden interno entre gentes del valle o de fuera llegados al valle. No deben olvidarse algunos datos muy significativos del estudio antropológico de los restos hallados en el Cerro de la Cabeza, relativos a determinados trabajos que exigían mucho esfuerzo, cargando pesos considerables y frecuentes sobre la espalda y la cabeza, trabajos que bien pudieron haber tenido que ver con la explotación de las malaquitas. En cualquier caso, lo que en principio no parecen indicar las características de los asentamientos es un clima tenso en el que la guerra pudiera haber sido un temor o un hecho frecuente que obligara a la elección de lugares bien defendibles e incluso a la construcción de algún tipo de defensas artificiales. Nada de eso se aprecia en el Valle Amblés. El ambiente "apacible" que muestran los asentamientos, casi todos ellos de muy pequeño tamaño, en realidad pequeñas granjas integradas por unidades familiares (Fabián 2006: 461-462), parecen hablar de distensión general, si bien la violencia latente y coyuntural no debe descartarse en absoluto (Guilaine y Zammit 2002). Los datos sugieren la existencia de una sociedad segmentaria organizada en torno a pequeños líderes de poder muy limitado y efímero (Garrido-Pena 2000), tal vez sustentado en la manipulación oportunista de cierto excedente, sin desdeñar que tuviera alguna base más ideológica y basada en la tradición. Son líderes que sólo tendrán algún papel más relevante y quizá menos inestable en el cambio del III al II milenio, a partir de un cambio de orientación de las estrategias de subsistencia, cuando el pastoreo cobra una importancia mayor, alentado por los cambios ambientales de tal coyuntura (Fabián et al. 2006). Pero como hemos expresado ya, tal vez fueran otras razones las que llevaran a un conflicto como el que aquí abordamos. Y en esas hipótesis tal vez podríamos ver pistas no sólo fijándonos en el tipo de flechas alóctonas y su presunta procedencia, sino también en otros elementos registrados en el Valle Amblés igualmente de procedencia externa, cuya localización apunta también a zonas próximas a las de la presunta procedencia de las puntas. Nos referimos a la presencia en el valle de un lote muy típico de elementos correspondientes al conocido como Horizonte de Rechaba que enlaza el NE de la península con la Meseta, en lo que es por ahora el único caso conocido de tal tipo de relación (Estremera y Fabián 2002). No debe olvidarse, además, que las variscitas de los yacimientos abulenses proceden, según los análisis, del conocido yacimiento de Palazuelo de las Cuevas, en la provincia de Zamora (Fabián 2006: 504).

Respecto a los otros enterramientos, poco más se puede decir que no sea constatar su existencia como tres casos más en la excepcionalidad general ya aludida que representan en conjunto. Teniendo en cuenta el hecho visto de la tumba colectiva, en el que se puede interpretar que la excepcionalidad viene marcada por un acontecimiento violento que precisó de otro ritual y una conmemoración, como parece marcar el túmulo, posiblemente debamos ver algo similar, aunque no tenga que ser necesariamente violento, en los otros casos, por más que no hayan dejado tantas evidencias para interpretarlo.

\section{Los enterramientos del Cerro de la Cabeza en su contexto geográfico y cultural}

El volumen de casos funerarios conocidos para el Calcolítico y para el conjunto de la Prehistoria Reciente en la Meseta no cuadra con la cantidad de hábitats, la duración de sus secuencias y el contin- 
gente demográfico esperable (Esparza 1990; Blasco 1997; Esparza et al. e.p.). Así pues, del reducido número de casos documentados cabe concluir que sólo una minoría recibió sepultura. No hay necrópolis normativas correspondientes a cada poblado y empieza a ser seriamente cuestionable el tópico de que la forma de enterramiento de ese momento en la zona en la que nos encontramos y su territorio limítrofe, esté relacionada, como norma, con el megalitismo. Los cuatro enterramientos del Cerro de la Cabeza implican por tanto una casuística que habría que incluir dentro del capítulo de las excepcionalidades en el registro funerario, o por decirlo con otras palabras, se trataría de "tumbas de relegación" (Delatre 2000).

Desconocemos los fundamentos concretos de la excepcionalidad que representan los casos del Cerro de la Cabeza, como la de otros que poco a poco van engrosando la lista de excepciones en el valle del Duero (Fabián, 1995; Herrán y Rojo, 1999; García Barrios, 2007; Esparza et al. 2008; Aliaga 2008; Carmona Ballestero 2012). Pero por más que se vaya engrosando la lista, siguen pareciendo excepcionales puesto que no se encuentran enterramientos masivos. El yacimiento madrileño del Camino de las Yeseras parece aportar alguna luz al esclarecimiento de esta cuestión. La distancia de éste al Cerro de la Cabeza es de poco más de 100 $\mathrm{km}$ y el ambiente general en la cultura material que se percibe en ambas zonas es similar. Allí vemos como a través de una investigación cuantitativamente muy amplia, el número de hallazgos funerarios es mayor, siendo además el registro variado en las formas y en los contenidos, con un panorama complejo nada fácil de interpretar (Blasco et al. 2011). Si unimos los datos de este yacimiento con el de todos los hallazgos producidos hasta ahora en la Meseta, comprobamos que durante el Calcolítico y el Bronce Antiguo que le sucede no hay un sistema de enterramiento definido y concreto. El tratamiento de la muerte adopta múltiples formas cuyo fundamento en la mayor parte de los casos parece muy particular, improvisándose posiblemente en ocasiones a partir de las circunstancias de la muerte, como sucedería con el Enterramiento 1 del Cerro de la Cabeza, por tratarse de un caso de violencia, siendo en otros casos las razones más complejas de averiguar. Así, producto de las circunstancias, se entierra en fosas a uno o a varios individuos, se agrupan niños o neonatos con mayores, se habilitan meros osarios como si procedieran de otro lugar y se quisiera dar a los huesos un destino final, se separan restos concretos y se llevan a los lugares de habitación o se mezclan, como si nada importaran, con restos de fauna en fosasbasureros, e incluso se aprovecha un determinado enterramiento individual para acompañarle de un cráneo. Y todo ello en un elenco que es precisamente ilimitado porque no parece una norma más o menos precisa de hacerlo, porque se puede improvisar sin aparente problema el destino final. Pero además hay casos que alertan sobre algo que pudo ser una tendencia de la que, a juzgar por características de alguno de los registros, no es fácil dar con nuevos casos. Nos referimos ahora a determinados hallazgos que hablan de agrupaciones considerables o al menos sustanciales de restos humanos. Arqueológicamente son grandes osarios donde han ido depositándose cadáveres durante cierto tiempo sin demasiado orden, desordenados, además, por el trasiego continuo de nuevas deposiciones. El contenedor es de forma variable pero no suele ser artificial. Podríamos decir que son en realidad "casas de muertos", lugares donde eran depositados la mayoría de los fallecidos de una comunidad. No podemos saber con exactitud si lo eran primariamente o de forma secundaria, e incluso de las dos formas, pero lo cierto es que se depositaban allí. Desde el punto de vista arqueológico son enterramientos colectivos al margen de lo megalítico, que ha sido tradicionalmente la forma de definir el contenedor funerario para el Neolítico y el Calcolítico. El yacimiento alavés de San Juan Ante Portam Latinam con una cronología del final del Neolítico (3365-3035 AC), en una zona donde son de sobra conocidos los casos megalíticos, que incluso llegan al tiempo de la cerámica campaniforme, es una buena muestra de ello (VV.AA. 2007). Parece ser también el caso del geográficamente más lejano del Camino del Molino, en Caravaca (Murcia), aunque con cronología posterior al alavés, en este caso de la segunda mitad del III milenio AC. (Lomba Mourandi et al. 2009). Ambos están en lugares fuera de los hábitats, donde los muertos son depositados sin más, alcanzando una gran cantidad (más de 300 en San Juan ante Portam Latinam y unos 1.300 en Caravaca). La generalización arqueológica de estas casas de muertos puede que sea pronto un hecho, mostrando lo que en realidad fue una constante cuyas variaciones en formas, capacidades o contenedores es posible que no fueran otra cosa que adaptaciones al lugar o simplemente puntualidades, más que planteamientos de fondo. Desconocemos si estos lugares serían el destino final de restos humanos después de permanecer en otros sitios o eran llevados allí sin más después de la muerte, entendiendo que eran ya tan solo despojos. En este sentido llama la atención el hecho de que tanto en San Juan Ante Portam Latinam, como también en el Camino del Molino, hayan aparecido algunos restos de supuestos ajuares entre el osario. ¿Indican la permanencia del cadáver en otro lugar y su 
posterior traslado al osario general con lo que le acompañaba? En principio no parece lo adecuado incluir ajuar a un cadáver que va a ser depositado sin más con otros muchos, desordenadamente, en algo que tiene que ver más con un depósito que con una tumba concreta y precisa.

Un asunto interesante de plantear es si la cantidad de cadáveres depositados en estas casas de muertos guarda relación directa con el tiempo de permanencia de una determinada comunidad en un lugar y con ello, naturalmente, un hecho sometido a debate como es la permanencia en mayor o menor medida de una comunidad en un sitio, es decir de la movilidad de las poblaciones prehistóricas. La relación entre esos hallazgos funerarios y la estabilidad de las poblaciones es un tema que precisa todavía de muchos datos, aunque parece apuntar en un sentido positivo. En relación a esto, pero también en lo que se refiere a la presencia de posibles casas de muertos en la zona objeto de este trabajo, debemos citar como posible el yacimiento calcolítico de El Tomillar (Bercial de Zapardiel, Ávila), del que se han publicado una parte de sus hallazgos (Fabián 1995, 2006, 2009). En El Tomillar se han excavado 33 estructuras negativas calcolíticas, que no son todas las que existen en el yacimiento, pero sí una buen aparte. Con ellas se ha estudiado también una estructura que podría ser una cabaña y se han detectado en el yacimiento otras tres más que resumirían posiblemente las cabañas existentes de una pequeña granja cuya vida debió tener lugar en torno a 2500 cal AC. Del conjunto de fosas, en dos han aparecido enterramientos fechados por cuatro dataciones calibradas a $2 \sigma$ en el intervalo $2800-2000 \mathrm{cal} \mathrm{AC}$, pero con una coincidencia de ambos en la combinación en torno a $2500 \mathrm{cal}$ AC. En uno de los casos hay restos de al menos 11 individuos y en el otro de 3 adultos y 5 niños recién nacidos. La fosa de los 11 individuos parece ser un enterramiento secundario por varias razones: por la escasa profundidad de la fosa excavada para depositarlos, por la parcialidad en el conjunto de los restos y por la cuidadosa colocación de dos cráneos sueltos al lado de otros dos que estaban en conexión anatómica junto a sus esqueletos correspondientes. Más que una fosa colectiva utilizada sistemáticamente, parece tratarse de una estructura de poca profundidad, excavada quizá con prisa o al menos sin demasiada pompa, para ocultar allí restos llevados de otra parte, restos que no estarían enterrados, porque muchos se hallaban en conexión anatómica, como si hubieran estado al aire libre o dentro de alguna construcción, sin enterrar, de forma que hubieran resultado parcialmente momificados. Si esto fue así, no llevaron a la fosa los restos de individuos completos porque seguramente no lo estaban tampoco en ese lugar.
Por acción de los animales allí dentro, por exposición a determinados animales en otro lugar, por una razón ritual en la que se les desmembró tomándose como reliquias algunas partes (en otra fosa había un fragmento de cadera y un húmero en conexión) o por otras razones que desconocemos, los cuerpos no estaban completos y por eso se habrían llevado de ese modo, incompletos, a su destino final. Este hecho se registra también en San Juan ante Portam Latinam (Rua 2007: 155).

De todo ello algo parece quedar claro: la diacronía de los restos de la Fosa 1, correspondientes a la comunidad que habitó El Tomillar. Según esto, ¿existió en alguna parte fuera del lugar de habitación una especie de casa de los muertos de la pequeña aldea y por alguna razón (tal vez el abandono del sitio) se quiso trasladar lo que quedaba de los muertos al lugar donde habían vivido? Pensar que esa casa de muertos estuvo donde han aparecido, como un lugar abierto, con los restos de alguna manera visibles y presentes, aunque fuera ocultos mediante una estructura sencilla, parece difícil de admitir ya sea sólo por razones higiénicas, si incluimos en ellas, por ejemplo, el hedor durante la descomposición, que ha obligado tradicionalmente a enterrar a los muertos, además de otras razones más poéticas (volver a la tierra) y religiosas. Esto sucedió en la Fosa 1, mientras en la 13 hubo otro enterramiento con 3 individuos adultos ( 2 mujeres y un hombre) y 5 neonatos, todos ellos depositados simultáneamente, aunque no se pueda garantizar un fallecimiento simultáneo. ¿Por qué esta distinción? ¿era la misma gente $u$ otra que estuvo poco después en el mismo sitio? ¿Estos lugares eran estables o recurrentes y en ese transcurso cabía en algo la modificación de los comportamientos morfológicos? No es fácil por ahora responder a estas cuestiones. De momento parece importante reseñar una idea que va cobrando forma, la de los enterramientos colectivos durante toda o buena parte del III milenio, observándose allí donde ha sido posible constatarlo, por ejemplo en el Camino de las Yeseras, como a partir de fechas en torno a 2300-2200 AC se producen algunos cambios, diversificándose más las formas de enterramiento, tendentes a lo individual y conviviendo tumbas sin ajuar con otras donde la cerámica campaniforme define el enterramiento (Ríos 2011). No tenemos tantos datos para el Valle Amblés y sus zonas limítrofes, pero puede decirse que con los datos disponibles la tendencia sería la misma o muy parecida, incluso con enterramientos campaniformes que lo certificarían, los de Aldeagordillo (Fabián 1992 y 2006: 319-326) y Fuente Olmedo (Martín y Delibes 1989; Díaz del Río 2001: 371).

Finalmente creemos que es importante plantear la relación entre estos enterramientos y el mundo 
campaniforme en su amplia faceta, puesto que las dataciones se encuadran dentro de un tiempo en el que esa cerámica circulaba de forma generalizada y porque, también, tenemos referencias geográficamente inmediatas y bien datadas de su uso funerario. Lo primero que hay que señalar es la abundancia de cerámica campaniforme en la zona excavada del Cerro de la Cabeza. Tanto en los niveles revueltos por las distintas culturas que habitaron el lugar como en las fosas con acumulaciones de desechos, la cerámica campaniforme puede decirse que es abundante para lo que suele ser habitual en los yacimientos calcolíticos de la zona. Siempre apareció fragmentada, formando parte de los rellenos de las fosas junto con otros fragmentos cerámicos lisos. Abundan los motivos puntillados geométricos, con buena representación también de incisos. Ahora bien, en ninguno de los enterramientos esta cerámica tuvo nada que ver que dejara huella, ni siquiera en forma de fragmentos que hubieran ido a parar allí casualmente. Quiere decirse que ninguno de los enterramientos merecía o le correspondía el uso de estas cerámicas a pesar de que circularan por el asentamiento, tal vez porque todavía no estaba "institucionalizada" la costumbre de usar esa posibilidad, siendo poco después cuando tuvo lugar.

Las fechas radiocarbónicas calibradas que les engloban a todos ellos abarcan un espacio temporal entre 2667-2134 cal AC, justo el tiempo en el que la cerámica campaniforme circulaba por la zona. Las fechas en ambiente funerario relacionadas con la cerámica campaniforme serían, en primer lugar, las de Aldeagordillo, a unos $4 \mathrm{~km}$ al este del Cerro de la Cabeza, en las que sobre huesos de uno de los inhumados la fecha calibrada dio 2200-1940 AC (Fabián 2006: 323). Con ésta son relacionables las fechas del enterramiento de Fuente Olmedo (Martín Vals y Delibes, 1989), a poco más de $70 \mathrm{~km}$ al norte, que le sitúan entre 2350 y el 1880 AC como fechas extremas (Fernández Manzano et al. 1997; Díaz del Río 2001: 371), pero con una coincidencia de fechas más marcada entre el 2200 y el 1940 AC aproximadamente, es decir coincidente con Aldeagordillo. También estarían las de los enterramientos con campaniforme del Camino de las Yeseras y de Humanejos, ambos en las inmediaciones de Madrid, que están en torno a ese tiempo también, excepto en un caso del primero, que parece más antiguo (2580-2460 AC) (Ríos Mendoza 2011). Remitiéndonos solo a lo evidente podríamos decir que hay una clara utilización funeraria de la cerámica campaniforme a partir del 2200 AC y en adelante; eso es justo después de que las evidencias conocidas nos digan que no sucedía esto mismo en la zona. Podemos decir esto con más garantías observando la similitud que ofrece el caso del Camino de las Yeseras. Debemos pensar que en torno a ese momento el campaniforme se incorpora de una forma decidida a lo funerario, pero evidentemente no a la generalidad de lo funerario. En Aldeagordillo se asocia a dos niños a los que se les concede tal honor, niños que no merecen, posiblemente por su condición de tales, ostentar las armas que acompañan a los vasos en otros casos de varones, pero sí la distinción que implicaba esa cerámica a la hora de enterramientos $\mathrm{y}$, además, la construcción del túmulo más ostentoso y central de un conjunto que conforma una especie de círculo, denotando una situación de clara diferencia también marcada por la posición elegida para el panteón y sus estructuras complementarias (Fabián 2006: 319-329) haciéndose más extremo en torno al 2440 AC. En el Valle Amblés, esta situación de distinguir a dos niños a través de un enterramiento singular va a coincidir con el abandono de los poblados calcolíticos tradicionales en favor de un patrón todavía no suficientemente definido en todas sus dimensiones y circunstancias, en el que se frecuentan sitios a cierta altura con buenos pastos estivales, marcada la situación en principio por un aumento de la aridez que fue creciente a medida que iba avanzando el Calcolítico (Fabián et al. 2006). Hay que preguntarse inevitablemente si la frecuencia de estos enterramientos ostentosos en los que participa el campaniforme está hablando de un contexto social diferente al de los poblados calcolíticos tradicionales, propiciado por nuevas condiciones sociales a partir de un cambio de orientación económica en el que la ganadería cobraría ventaja sobre la agricultura. Los enterramientos del Cerro de la Cabeza estarían en el límite cronológico de la nueva situación, sino alguno dentro ya de ella (el 3 y el 4), pero pertenecientes a un ambiente donde la diferenciación no se marcaba en lo funerario de una forma tan patente como se marcó en algunos individuos después, tal vez ya en otro contexto económico, con sus derivaciones y connotaciones, y social, derivado de todo ello. ¿Hemos de ver en lo conocido para el Cerro de la Cabeza -y extrapolable a sitios con similar cronología, como El Tomillar, en Bercial de Zapardiel (Ávila)- los umbrales de un momento de transformación del contexto económico y social, marcado hasta entonces por menos desigualdades sociales o por un menor interés en representarlas a través de la muerte? 


\section{Notas}

1. La intervención de urgencia fue dirigida por D. Francisco Javier Sanz, de la empresa Strato. En la excavación de las estructuras funerarias que aquí se abordan participamos directamente los dos firmantes de este trabajo.

2. Agradecemos a nuestro amigo Pepe Muñoz el interés y el tiempo dedicado para realizar este dibujo en detrimento de su tiempo siempre escaso.

3. Agradecemos a D. Antonio Rubinos del Laboratorio de Geocronología del CSIC (Instituto de Química Física Rocasolano) sus indicaciones y comentarios al respecto.

\section{REFERENCIAS BIBLIOGRÁFICAS}

Aliaga Almela, R. (2008): El mundo funerario calcolítico de la región de Madrid. Cuadernos de Prehistoria y Arqueología de la Universidad Autónoma de Madrid, 34: 23-39.

ArIÉs, P. (1983): El hombre ante la muerte. Taurus, Madrid

Armendariz Martija, J. E; Irigaray Soto, S. (1994) La arquitectura de la muerte. El hipogeo de Longar (Viana, Navarra), un sepulcro colectivo de 2500 a.C. Centro de Estudios Tierra de Estella.

Beguiristain Gurpide, M.A. (1987): Nuevos datos sobre el ritual funerario durante el Neolítico y la Edad del Bronce en Navarra. I Congreso General de Historia de Navarra, Pamplona 1986. Anejo 7: 205-215.

Blanco González, A. (2008): Tendencias del uso del suelo en el Valle Amblés (Ávila, España). Del Neolítico al Hierro Inicial. Zephyrus, LXII: 101-123.

Blasco Bosqued, C. (1997): Manifestaciones funerarias de la Edad del Bronce en la Meseta. Saguntum, 30: 173190.

Blasco, C., Sánchez Capilla, M. L., Calle, J., Robles, F. J., González, V.M.; González, A. (1991): Enterramientos del Horizonte Protocogotas en el Valle del Manzanares. Cuadernos de Prehistoria y Arqueología de la Universidad Autónoma de Madrid 18, 55-112.

Blasco, C.; Liseau, C.; Ríos, P. (eds) (2011): Yacimientos calcolíticos con campaniforme en la región de Madrid: nuevos estudios. Patrimonio Arqueológico de Madrid nº 6, Madrid.

Bueno Ramírez, P.; Balbín Behrmann, R. de; Barroso Bermejo, R.; Alcolea Quintana, A.; Casado Mateos, A.B. (2000): Dólmenes en Alcántara (Cáceres). Un proyecto de consolidación e información arqueológica en las comarcas extremeñas del Tajo. Balance de las campañas de 1997-1998). Extremadura Arqueológica VIII. Megalitismo en Extremadura (Homenaje Elías Diéguez Luengo): 129-168.

Carmona Ballestero, E. (2012): Las comunidades campesinas calcoliticas en el valle medio del Arlanzón (cal. 3000-1900 AC). Transformaciones y procesos históricos. Tesis doctoral inédita, Universidad de Burgos. URL: http://dspace.ubu.es:8080/tesis/handle/10259/175 [acceso: marzo 2012]

ChÉNIER, A. (2009): Bones, people and communities: Tensions between individual and corporate identities in secondary burial ritual. Nexus: The Canadian Student Journal of Anthropology, 21: 27-40.

Delatre, V. (2000): De la relégation sociale à l'hypothèse des offrandes: l'exemple des dépôts en silos protohistoriques au confluent Seine-Yonne (Seine-et-Marne). Revue Archéologique du Centre de la France, 39: 5-30.

Delibes de CAstro, G. (1987): Sobre los enterramientos del grupo campaniforme de Ciempozuelos: diversidad y tradición. El origen de la metalurgia en la Península Ibérica (M. Fernández-Miranda, ed.), Fundación Ortega y Gasset, Madrid, vol. II: 37-51.

Díaz del Río EsPañol, P. (2001): La formación del paisaje agrario: Madrid en el III y II milenios BC. Arqueología, Paleontología y Etnología, Series de la Consejería de las Artes de la Comunidad de Madrid no 9.

Esparza Arroyo, A. (1990): Sobre el ritual funerario de Cogotas I. Boletín del Seminario de Estudios de Arte y Arqueología, LVI: 106-143

Esparza Arroyo, A.; Delibes De Castro, G.; Velasco Vázquez, J. (e.p.): HUM 2005-00139: Planteamiento y primeros resultados de un proyecto de investigación sobre la muerte en Cogotas I. Cogotas I: una cultura de la Edad del Bronce en la Península Ibérica (G. Delibes de Castro, J. Fernández Manzano y J. A. Rodríguez Marcos, eds.), Universidad de Valladolid, Valladolid.

Esparza Arroyo, A.; Delibes De Castro, G.; Velasco Vázquez, J.; Cruz Sánchez, P.J (2008): Historia de un golpe en la cabeza: sobre el enterramiento calcolítico del hoyo 197 de "El Soto de Tovilla" (Tudela de Duero, Valladolid). Boletín del Seminario de Estudios de Arte y Arqueología, LXXIV: 9-48. 
Estremera Portela, M.S.; Fabián García, J.F. (2002): El túmulo de la Dehesa de Río Fortes (Mironcillo, Ávila): primera manifestación del Horizonte Rechaba en la Meseta Norte. Boletín del Seminario de Estudios de Arte y Arqueología, LXVII: 9-48.

FABIÁn GarcíA, J.F. (1992): El enterramiento campaniforme del Túmulo 1 de Aldeagordillo (Ávila). Boletín del Seminario de Estudios de Arte y Arqueología, LVII: 97-132.

FABIÁn GARCíA, J.F. (1995): El aspecto funerario durante el Calcolítico y la Edad del Bronce en el Sur de la Meseta Norte. El enterramiento colectivo en fosa de El Tomillar (Bercial de Zapardiel, Ávila) en el marco cultural de la Prehistoria reciente del Sur de la Meseta Norte española. Universidad del Salamanca, Col. Estudios Históricos y Geográficos no 93.

FABIÁn GarcíA, J.F. (1999): Actividades arqueológicas en Castilla y León 1995-1996. Ávila. Numantia, 7: $221-229$.

Fabí́n García, J.F. (2003): El Calcolítico en el suroeste de la Meseta Norte: Fuente Lirio (Muñopepe, Ávila). Numantia, 8: 9-50.

FABIÁn García, J.F. (2006): El IV y el III milenio AC en el Valle Amblés (Ávila). Arqueología en Castilla y León. Monografías $\mathrm{n}^{\mathrm{o}} 5$.

Fabián García, J.F. (2009): Hace 4600 años, en El Tomillar (Bercial de Zapardiel, Ávila). Institución Gran Duque de Alba, Ávila.

Fabián García, J. F.; Blanco González, A.; López Saez, J.A. (2006): La transición Calcolítico-Bronce Antiguo desde una perspectiva arqueológica y ambiental: el Valle Amblés (Ávila) como referencia. Arqueología Espacial, 26: 37-56.

Fabián García, J.F.; Strato; Blanco GonzÁlez, A. (2010): El enterramiento en fosa del Cerro de la Cabeza (Ávila). La cuestión funeraria en el Bronce Final / Hierro I en el sur-oeste de la Meseta Norte. Arqueología, Sociedad, Territorio y Paisaje. Estudios sobre Prehistoria Reciente, Protohistoria y Transición al Mundo Romano en Homenaje a María Dolores Fernández-Posse (P. Bueno, A. Gilman, C. Martín y J. Sánchez Palencia, eds.), CSIC, Madrid: 183-194.

Fernández Manzano, J; Herrán Martínez, J.I.; Orejas Saco del Valle, A.; Hernansanz Sanz, M. y Paradinas, S. (1997): Minería y poblamiento calcolítico en Ávila de los Caballeros. II Congreso de Arqueología Peninsular, Tomo II, Zamora.:527-542.

García BARrios, A.S. (2007): Los inicios de la Edad del Cobre en el valle Medio del Duero: una aproximación a los modo de vida en el centro de la Meseta en los albores de la metalurgia. Tesis Doctoral inédita, Universidad de Valladolid.

García Barrios, A.S. (2008): El mundo ritual en la Prehistoria Reciente: una reflexión a propósito del caso de "Los Cercados" (Mucientes, Valladolid). I Jornadas de Jóvenes en Investigación Arqueológica: Dialogando con la Cultura Material (3-5 septiembre 2008), Madrid: 191-198

Garrido-Pena, R. (2000): El Campaniforme en la Meseta Central de la Península Ibérica (c. 2500-2000 A.C.). British Archaeological Reports, Oxford.

Garrido-Pena, R.; Rojo, M.A.; García, I.; Tejedor, C. (2011): Drinking and Eating Together: The Social and Symbolic Context of Commensality Rituals in the Bell Beakers of the Interior of Iberia (2500-2000 cal BC). Guess Who's Coming to Dinner. Feasting Rituals in the Prehistoric Societies of Europe and the Near East (Aranda, G., Montón, S. y Sánchez-Romero, M.. eds.), Oxbow Books, Oxford: 109-129.

Gómez de RuedA, I. (1997): Ritos exequiales. No creyentes. No bautizados y suicidas". Revista Murciana de Antropología, 2: 179-187.

Gómez García, J.; SAnz Ruiz, P. (1994): Valdeprados (Aldea del Rey, Ávila). Un nuevo enterramiento en la submeseta Norte. Cuadernos Abulenses 21: 81-116.

Guilaine, J.; Zammit, J. (2002): El camino de la guerra. La violencia en la Prehistoria. Ariel, Barcelona.

Herrán Martínez, J.I.; Rojo Guerra, M.A. (1999): ¿Una nueva tumba en fosa calcolítica? El hallazgo de Colmenares, Portillo (Valladolid, España) y su contexto arqueológico. Estudios Pre-históricos, VII: 111-124

Juan Cabanilles, J. (2009): El utillaje de piedra tallada en la Prehistoria Reciente valenciana. Aspectos tipológicos, estilísticos y evolutivos. Serv. Inv. Preh. de Valencia, Serie Trabajos Varios no 109, Valencia.

LARRÉn IzQUIERDo, H. (Coord.) (1999): Arqueología e infraestructura agraria en el Valle del Tera (Zamora). Ministerio de Medio Ambiente, Madrid.

Larsson, A.M. (2003): Secondary Burial Practices in the Middle Neolithic. Causes and Consequences. Current Swedish Archaeology, 11: 153-170. 
Liseau, C.; Blasco, C.; Ríos, P.; Vega, J.; Menduiña, R.; Blanco, J. F.; Baena, J., Herrera, T.; Petri, A.; Gómez, J. L. (2008): Un espacio compartido por vivos y muertos: El poblado calcolítico de fosos de Camino de las Yeseras (San Fernando de Henares, Madrid). Complutum, 19 (1): 97-120.

Lomba Maurandi, J.; Lopez Martinez, M.; Ramos Martinez, F.; Avilés Fernandez, A. (2009): El enterramiento múltiple, calcolítico, de Camino del Molino (Caravaca, Murcia). Metodología y primeros resultados de un yacimiento excepcional. Trabajos de Prehistoria $n^{\circ} 66$ (2): 143-159.

Martín Valls, R.; Delibes de CAstro, G. (1989): La cultura del Vaso Campaniforme en las campiñas meridionales del Duero. El enterramiento de Fuente Olmedo (Valladolid). Monografías del Museo Arqueológico de Valladolid, Valladolid.

PeÑa y Montes de OcA, C. DE la (1986): La necrópolis de los Churuletes (Purchena, Almería). Cuadernos de Prehistoria de la Universidad de Granada, 11: 73-170.

Poyıl, M. (2009): Farewell Ritual and Transmigrating Souls: Secondary Funeral of the Attappadi Kurumbas. Anthropologist, 11(1): 31-38.

Ríos Mendoza, P. (2011): Nuevas fechas para el Calcolítico de la región de Madrid. Aproximación cronológica a los primeros poblados estables. Yacimientos Calcolíticos con campaniforme de la región de Madrid: nuevos estudios (C. Blasco, C. Liseau y P. Rios, eds.), Patrimonio Arqueológico de Madrid nº 6: 73-86.

Robledo, B.; Jori, J.; Trancho, G.J. (2000): Caracterización biomorfológica y estado de salud de la población calcolítica del Cerro de la Cabeza (Ávila). Universidad Complutense de Madrid. Departamento de Biología Animal I (Antropología), Informe inédito.

RuA DE LA, C. (2007): La inhumación colectiva de San Juan ante Portam Latinam (Laguardia, Álava): Aspectos paleodemográficos y su contribución a la interpretación del ritual funerario. San Juan ante Portam Latinam (Laguardia, Álava): Una inhumación colectiva prehistórica en el Valle Medio del Ebro (VV.AA.), Memorias de yacimientos alaveses $n^{\circ} 12$, Vitoria.

Schroeder, S. (2001): Secondary Disposal of the Dead: Cross-Cultural Codes. World Cultures 12 (1): 77-93.

Trancho, G.J. y Robledo, B. (1999): Paleodieta: Estudio del patrón alimenticio en El Cerro de la Cabeza (Ávila). Universidad Complutense de Madrid, Departamento de Biología Animal I (Antropología), Informe inédito.

Vallespi, E.; Ciudad, A.; García, R.; Caballero, A. (1985): Industrias líticas talladas del Eneolítico y Bronce en la provincia de Ciudad Real. Oretum, 1: 231-246.

Velasco Vázquez, J.; Alberto Barroso, V.; Quintana Andrés, P. (2003): La mala muerte. El Depósito funerario de la calle Rosarito de la Isleta. Ediciones del Cabildo de Gran Canaria, Las Palmas de Gran Canaria.

VV.AA. (2007): San Juan ante Portam Latinam (Laguardia, Álava): Una inhumación colectiva prehistórica en el Valle Medio del Ebro. Memorias de yacimientos alaveses $n^{\circ} 12$, Vitoria. 